\title{
Metabolites from Macroalgae and Its Applications in the Cosmetic Industry: A Circular Economy Approach
}

\author{
Catarina Lourenço-Lopes ${ }^{1}{ }^{\circ}$, Maria Fraga-Corral ${ }^{1,2}{ }^{\infty}$, Cecilia Jimenez-Lopez ${ }^{1,2}{ }^{(}$,

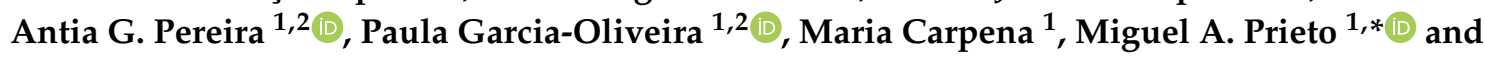 \\ Jesus Simal-Gandara 1,*(D) \\ 1 Nutrition and Bromatology Group, Analytical and Food Chemistry Department, Faculty of Food Science and \\ Technology, University of Vigo, Ourense Campus, E-32004 Ourense, Spain; c.lopes@uvigo.es (C.L.-L.); \\ mfraga@uvigo.es (M.F.-C.); cecilia.jimenez.lopez@uvigo.es (C.J.-L.); antia.gonzalez.pereira@uvigo.es (A.G.P.); \\ paula.garcia.oliveira@uvigo.es (P.G.-O.); maria.carpena.rodriguez@uvigo.es (M.C.) \\ 2 Centro de Investigação de Montanha (CIMO), Instituto Politécnico de Bragança, Campus de Santa Apolonia, \\ 5300-253 Bragança, Portugal \\ * Correspondence: mprieto@uvigo.es (M.A.P.); jsimal@uvigo.es (J.S.-G.)
}

Received: 18 July 2020; Accepted: 18 August 2020; Published: 24 August 2020

check for updates

\begin{abstract}
Marine macroalgae are a suitable source of ingredients due to their huge diversity, availability and nutritional and chemical composition. Their high content in proteins, carbohydrates and vitamins, but also in secondary metabolites such as phenolic compounds, terpenoids or pigments, make them great candidates for industrial applications. The cosmetic industry is one of the biggest in the world and the search for new ingredients is constantly growing as the consumer trend now is going back to those traditional cosmetics with a more natural composition. Moreover, the concept of a circular economy is also gaining importance due to the unsustainable situation of the natural resources. Although macroalgae are already used in cosmetics, especially as thickening and gelling agents, they possess an unexplored potential, not only as excipients and additives but also as a source of new active ingredients. In this context, macroalgae are considered in many cases as resources still underexploited and they could even be obtained from the waste of other industrial sectors and be used for recovering active molecules. Therefore, the aim of this review is to compile information about the different macroalgae metabolites and their possible applications in the cosmetic industry, which could employ circular economy models.
\end{abstract}

Keywords: macroalgae; cosmetics; macroalgae applications; active ingredients; metabolites; circular economy; sustainable use of natural resources; waste reduction

\section{Perspectives of the Use of Macroalgae for Industrial Applications}

Marine ecosystems possess a huge diversity of species. About 225,000 eukaryotic marine species have been taxonomically classified and validated but it has been estimated that this number can reach nearly 700,000. Algae contribute to aquatic biodiversity with nearly 44,000 species described, even though this value seems to be underestimated since another 28,500 species are expected to be characterized [1]. One group of the algae, macroalgae, also named seaweed, are a diverse group of aquatic macroscopic eukaryotes. They are considered primary producers and also represent the habitat of many microorganisms that live on their surface. Thus, they represent an important part of the basis of the marine trophic chain. They are ubiquitous. Macroalgae can live at the air-water interface or be attached to some solid substrate, and they can be found in superficial waters but also the deep sea, reaching profundities of $180 \mathrm{~m}$. Macroalgae are commonly classified as autotrophic since most of them are photosynthetic organisms, showing higher productivity efficiencies, even greater than the most 
productive land plants [2-4]. However, as some representatives live in very deep areas, they need to be chemoheterotrophic using organic molecules to obtain metabolic energy. Nowadays, macroalgae can be classified based on many different criteria, such as cell properties, pigments production, life cycle, habitat, etc. Commonly, they are divided into three categories, based on their pigmentation: green (Chlorophyceae), red (Rhodophyceae) and brown macroalgae (Phaeophyceae) [2-4].

The human consumption of macroalgae has a historical path in which archaeological evidence dating from 14,000 years BP and writing reports from 600 AD have been found [5]. Nowadays, the use of macroalgae has been extended not just for feeding purposes but for cosmetic, industrial and pharmaceutical aims. Macroalgae represent a remarkable source of minerals (7-36\%), lipids (1-5\%), polysaccharides (15-76\%) and proteins (5-47\%) [6-8]. Macroalgae contain a few important minerals at quite high concentrations, such as iodine, calcium, iron, copper, and magnesium. The macroalgae lipid composition mainly includes two polyunsaturated fatty acids (PUFAs), omega 3 and omega 6 acids, recognized as molecules involved in the prevention of cardiovascular diseases, osteoarthritis and diabetes. Besides, other fatty acids, like alpha-linolenic acid ( $\omega 3 \mathrm{C} 18: 3$ ), have been found in green macroalgae, and eicosapentaenoic (EPA, $\omega 3$ C20:5) and arachidonic acid ( $\omega 6$ C20:4) in red and brown ones. Seaweeds are also well-known polysaccharide producers, being commonly applied as hydrocolloids in different industries. The most abundant ones are alginates (brown macroalgae), carrageenans and agar (red macroalgae), while fucoidans and laminarin (brown macroalgae), xylans, and floridean starch (red macroalgae), and ulvans and xylans (green macroalgae) represent minor storage polysaccharides. Their protein content is highly dependent on the macroalgae type, since brown ones have low amounts (5-15\% of the dry weight), whereas green and red can reach values near to $50 \%$ (10-47\% of the dry weight) [7,8]. Among these nutritional values, macroalgae have a high content in micro-nutrients, which includes vitamins (mainly B3, B9, B12, C and E) and antioxidants, such as polyphenols (the most relevant ones are the phlorotannins, which can reach up to $15 \%$ of the dry matter) or pigments (carotenoids and chlorophylls). Besides, in the last decades, over 4000 metabolites have been extracted from, mostly, red and brown, but also some from green macroalgae, and have been listed in the natural product database, DNP (the Dictionary of Natural Products). Macroalgae represent an inestimable source of biomolecules and micro-nutrients with biological and biochemical functions. Nonetheless, season and geographical distribution largely influence the chemical composition of macroalgae. The factors that mostly affect the synthesis of bio-compounds during the culture of macroalgae are water temperature, salinity, nutrients content, light intensity, $\mathrm{pH}, \mathrm{CO}_{2}$ concentration, available minerals and the presence of contaminants [9-11].

Considering the composition of macroalgae, they have been considered a promising source of compounds that could be employed to solve some current industry issues. Nowadays, consumers' concerns about the use of synthetic molecules have risen and they have started to demand their replacement for natural ones be associated with positive health effects. Macroalgae extracts are rich in biomolecules that have shown to possess a wide range of bioactivities, such as anti-inflammatory, anti-microbial, anti-diabetic, anti-cancer, neuroprotective, anti-aging, photo-protection, lipolysis, moisturizing and whitening, among many others. Thus, ingredients obtained from macroalgae could result in interest from different industries, including the cosmetic sector [7,8,12-14]. Additionally, the concept of a circular economy has also gained importance due to the current unsustainable situation: pollution increases every day, resources are finite and waste accumulation is one of the main challenges for the planet [15]. In this regard, various approaches have been proposed. On the one hand, invasive macroalgae species could be considered as residues as it is necessary to remove them from coastal systems and they do not have a specific use. Thus, species such as Sargassum spp. have been proposed as a source of bio-compounds with different applications $[16,17]$. The other scope is related to the underexploited or understudied state of marine organisms. The sea still is a partially undiscovered ecosystem and marine macroalgae have been presented as excellent sources of bioactive compounds allowing the use of macroalgae without any commercial value currently. Therefore, they could be considered as an emerging sustainable use of natural resources [18]. Lastly, as aforementioned, 
seaweeds are known for their polysaccharides production and their application to the hydrocolloids industry. In this context, different studies have pointed out the disposal of residual biomass, effluents and other washing waters derived from hydrocolloids, biofuel and food industries. These residues could still contain bio-compounds that could be recovered after a downstream process [19-21]. In Figure 1, a schematic representation of the process of recovering bioactive compounds and their incorporation as active ingredients, additives or excipients to cosmetic products is shown. So, considering the need for a circular economy, marine macroalgae (either invasive, natural or as industry by-products) can be proposed as a sustainable source of bio-compounds.

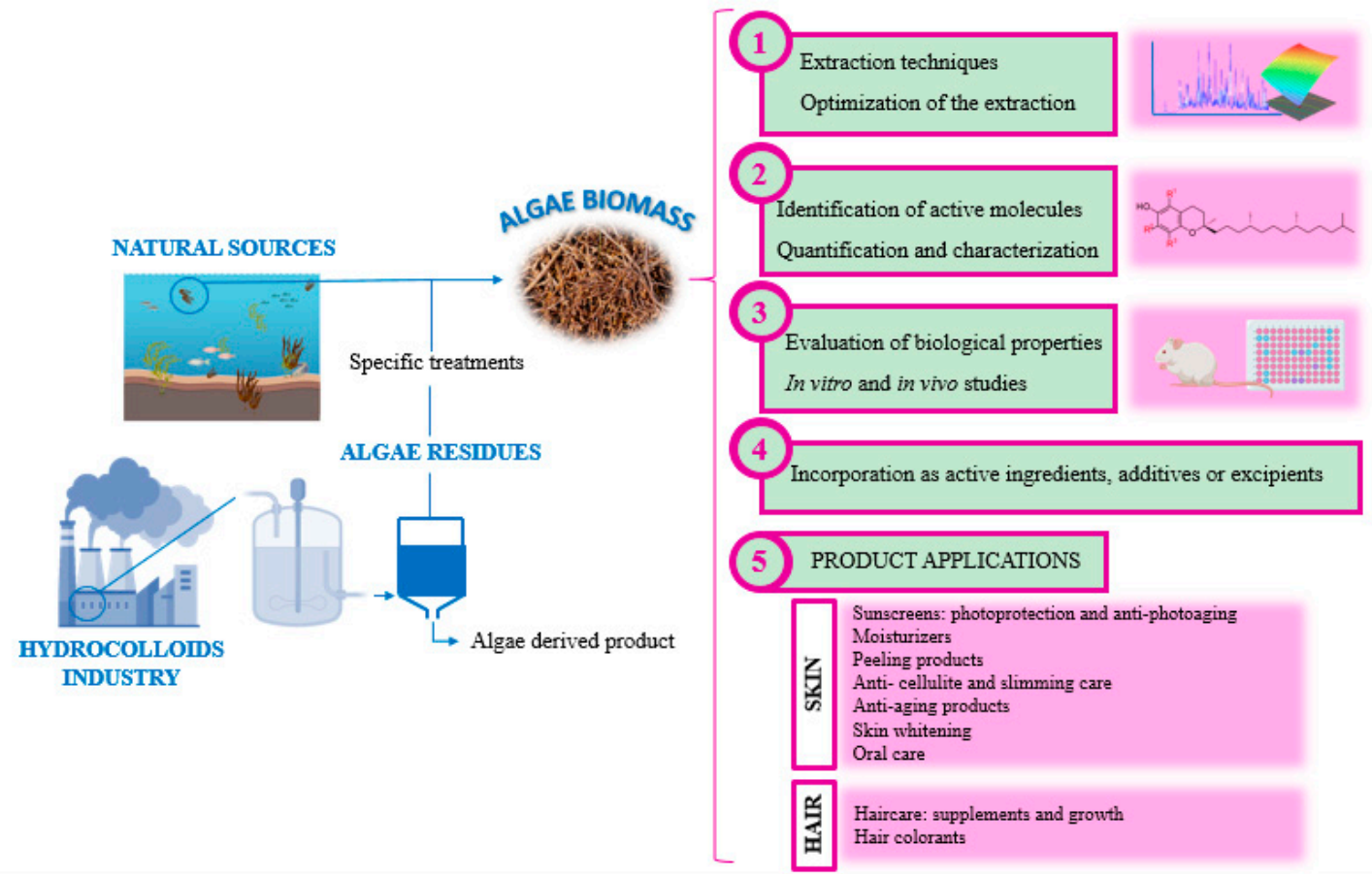

Figure 1. Visual representation of the process for the incorporation of new compounds as active ingredients, additives or excipients to cosmetic products. Compounds can be obtained from the environment or as by-products of the food and hydrocolloids industry.

The aim of this review was to compile the current knowledge about macroalgae metabolites and their possible applications in the cosmetic industry. The systematic search was carried out consulting several databases, like ScienceDirect, Scopus and PubMed, as well as free-access repositories like Google Scholar, basing the research on keywords like "macroalgae; cosmetics; seaweed metabolites; macroalgae cosmetic applications; macroalgae cosmetic product applications", and only articles referring to macroalgae were taken into consideration, excluding the ones about microalgae. In the ScienceDirect database (consulted in August 2020), more than 8500 documents were published with the keywords "algae cosmetics" and the majority corresponded to research articles (45.2\%) and book chapters (23.1\%), followed by reviews (17.6\%). The bibliographic references were chosen among them, according to their interest and in concordance with the covered topics. Besides, a few patents and statues were also consulted. The broad information recompiled was then further organized in the different sections present in this article. So, after analyzing all the data available regarding this topic, we can conclude it is a current topic even though it is still a growing filled with much research to be made, and with further applications yet to be discovered.

\section{Current Trends in the Cosmetic Industry and Its Main Objectives: Skin and Hair}

Around the world, different regulations have provided the meaning of cosmetic products, depending on their legal frames. In the European Union, a cosmetic product is defined as "any 
substance or mixture intended to be placed in contact with the external parts of the human body (epidermis, hair system, nails, lips and external genital organs) or with the teeth and the mucous membranes of the oral cavity with a view exclusively or mainly to cleaning, perfuming, changing their appearance, protecting, keeping in good condition or correcting body odors" [22]. In Japan and the United States, the Federal Food, Drug and Cosmetic Act, has provided a similar definition with equivalent functions to those aforementioned. However, it is important to notice that, unlike medicine, a cosmetic product cannot claim to have any therapeutic action. Nevertheless, cosmetics are very often needed in the latter stages of different dermatological pathologies, such as acne or atopic eczema, where these are used to combat drying out of the skin caused by the treatment or to make a barrier that retains the dermocorticoids [23].

Historically, cosmetics have been used for thousands of years, driven by the pursuit of beauty. Even though the concept of beauty has evolved a lot along time, it is still a biologic trait based on Darwinian principles. Features composing a beautiful and healthy face are considered biological signals and suggest a possible correlation with social judgments [24]. Currently, the trend in the cosmetic sector is characterized by continuous growth that is proportional to the development of the middle classes in many emerging countries. The cosmetic industry is one of the biggest in the world and has been estimated to generate an annual turnover of 170 billion American dollars, according to the Eurostaf analysis [25]. This economic tendency is expected to continue or even to increase since cosmetics is a field in which innovation represents the main tool and permits the unceasing update of the products. The search for novel ingredients is constant, mainly due to two reasons: the first one based on marketing criteria, and the second one, the need of replacing molecules that have been banned or have become distrusted by consumers. In recent years, consumers have become suspicious of several chemical ingredients and many want to go back to fundamental or basic cosmetics, with a simple composition and natural ingredients. This trend of consumption has been triggered in the last years due to the direct implication that using natural compounds has for the environment and society since they represent sustainable and ethically designed products [26]. Therefore, the future of cosmetics is parallel to the use of natural ingredients. Considering this fact, macroalgae are rich in bioactive compounds; so, they constitute a very interesting matrix that could be exploited for obtaining functional ingredients with potential applications in cosmetic [23]. Macroalgae represent an important source of cosmetic thickening ingredients, water-binding agents and antioxidants. From this point of view, these organisms are a sustainable source of ingredients since they can be cultivated on seashores on a large scale with very little environmental impact and at a low cost. They grow relatively rapidly and it is possible to control the synthesis of their bioactive compounds, which is mainly influenced by the availability of nutrients and the application of some stress conditions, such as excess of light [26]. Additionally, from a legal point of view, macroalgae has been further considered as a vegetal extract and thus they do not have tight restrictions for their cosmetic use, even though cosmetic products (including seaweed extracts) must comply with strict rules concerning the use of chemical substances described in EU regulation No. 1223/2009 on cosmetic products. Nevertheless, the most exigent bottleneck to successfully reach the cosmetic market is to satisfy the consumers' demands that look for products containing nontoxic as well as effective natural ingredients [13].

The main targets of cosmetics are the skin and the hair. The skin is the most extensive organ in the human body, with an approximated surface area of $2 \mathrm{~m}^{2}$ that represents $2 \mathrm{~kg}$ of mass for the average adult. The skin is responsible for providing a barrier between the environment and the internal organs. This important function that offers protection and stability to the organs is due to the multiple strata that form the skin: the epidermis (consisting of five strata, namely, basal, spinous, granular, lucid and corneum), dermis and hypodermis [27]. The other physical function of the skin is as a sense organ with a relevant role in the sensory perception. Besides, the skin is the main character in the physical image that we convey of ourselves, hence the importance of disciplines such as dermatology and cosmetology [23]. Human skin is a dynamic tissue, in which the cells of the epidermis undergo differentiation, based on gradual cell death that occurs due to the malnourishment 
of the outer epidermis layers. Dead cells remain on the skin surface for approximately two weeks. The ongoing process of keratinization that lasts from 28 to 30 days is responsible for the natural renewal of the epidermis. Keratinization and exfoliation of dead skin cells determine the color of the skin, smoothness of its surface, water retention and the general appearance of the complexion [28]. The "skin aging" definition is usually related to the thinning and/or general degradation of the dermis that occurs through several processes, involving a decrease in collagen gene expression, lower fibroblast activity and fibroblast regeneration, as well as shrinking of the lamellar barrier, which is shown in the inability of the skin to retain moisture. Consequently, the term "anti-aging" refers to an effect that counteracts skin aging; that is, acting against the above effects for retaining smooth and healthy skin [29]. Aged skin is characterized by a reduced content of collagen, with Type I and III as the main structural proteins in the skin [30]. One of the causes of collagen degradation is exposure to ultraviolet A (UVA) radiation, which involves wrinkle formation. Thus, agents that stimulate collagen synthesis represent crucial ingredients in active cosmetics since they provide an anti-aging effect [31]. Furthermore, antioxidant-enriched formulations administered topically by cosmetics or by dietary supplements could exert an antioxidant/protective effect on the skin by decreasing the oxidative stress, which is one of the major mechanisms for skin aging [32].

Hair grows in groups called follicular units and each unit can grow individually or in groups of 2 to 5 hairs. Each healthy hair is composed of three main concentric regions: the medulla, cortex and cuticle. The medulla is situated at the center of the hair, formed of transparent cells and air spaces. The following layer is the main one: the cortex. It stores the hair's moisture, as well as providing bulk and mechanical strength since it is formed by keratin, a highly structured protein. This protein is responsible for hair resistance and elasticity. It has been stated that a single hair can hold up to $100 \mathrm{~g}$, which means that a full head of hair can hold more than 10 tons of weight. Besides, the cortex contains the cells with different types of melanin granules; the variation in their number and distribution gives the hair fiber its variable pigmentation. Finally, the outer layer, the cuticle, is composed for 8-10 overlapped layers of flat cells that can last, when intact, up to 6 years. The cuticle reflects light when cell-based scales maintain its smoothness, which gives hair its shiny healthy appearance [33]. A simple scheme of the structure of skin and hair is shown in Figure 2.

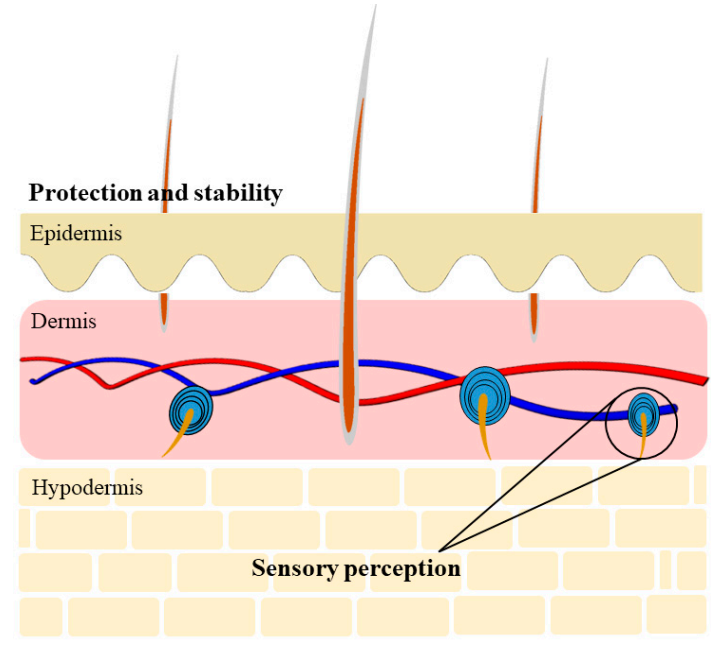

(A) Skin structure

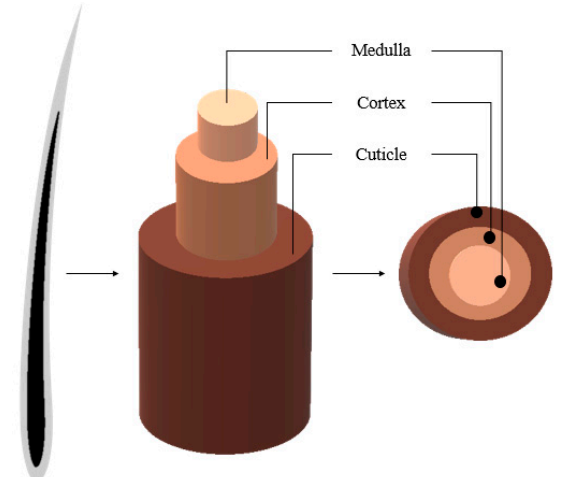

(B) Hair structure

Figure 2. Structures of the different parts that form the skin (epidermis, dermis and hypodermis) and hair (medulla, cortex and cuticle). 
Even though shiny and healthy hair depends on several aspects, taking care of the cuticle is essential since it also provides the softness, comb and style, while the damage of the fibers leads to a loss of structure and split ends. This damage provokes the aging of hair that may be due to age-related thinning agents such as genetic (androgenetic alopecia) or hormonal changes, but mostly caused by external factors including hair color, weathering, ultraviolet (UV) exposure, grooming habits or the choice of inappropriate haircare products. Styling tools like hair dryers, straightening and curling irons are responsible for the expansion of moisture creating microcavities within the shaft. Microcavities are induced by the high temperatures that these devices reach, which are especially damaging when applied to combing and brushing wet hair, applying force and heat on the tip that may trigger the development of trichoschisis. Trichorrhexis nodosa is a hair defect with a genetic basis but mostly precipitated by environmental factors. This affection implies the loss of the cuticle and the damage of the cortex due to the repeated temporary disruption of hydrogen bonds [34,35].

The care of healthy hair has always been important from an esthetic point of view. Throughout humankind's history, different ancient civilizations have left representations that confirm hair relevance. The hieroglyphic testimonials of the Egyptians revealed the importance of hair, not only because of the visual effect but also because of the cultural and erotic symbolism connected with it. Hair was not only a question of fashion for the ancient Romans. It was used as a symbol of beauty, class, virility and intellect, and in modern culture having a full head of hair is often associated with desirable qualities like youthfulness and vitality. Healthy hair is usually associated with a healthy scalp, and although good care is of prime importance to keep both in good condition, the public is not knowledgeable about how to appropriately care for them. In fact, hair loss has been recognized as a source of distress that may affect people's life, causing social anxiety and interfering with their wellbeing [35].

Therefore, the cosmetic sector, with a strong and ubiquitous presence in daily life, requires the inclusion of innovative and natural ingredients that reinforce the beneficial and healthy properties of its products to widen the application of their products, to reach more costumers and satisfy their exigent demands. In this context, seaweed represents an economical, sustainable and ecological source of natural biomolecules with a huge range of bioactivities to enhance the quality of the cosmetic products.

\section{Macroalgae-Based Metabolites of Interest for Cosmetics}

\subsection{Polysaccharides}

Polysaccharides (PS), commonly known as sugars, are important when formulating cosmetics since they can form a gel structure called a hydrogel or hydrocolloid. The presence of PS permits to immobilize water using insoluble polymers with the consequent moisturizing effect. The PS utilized in cosmetics can be mainly classified into two groups: functional and active. Functional PS are those with applications in the formulation technology and stabilization, while the active PS are ingredients that improve the features of the cosmetic product, such as PS with moisturizing and antioxidant capacity [36,37]. Seaweeds have been described to contain a diverse range of structural and functional PS, for example, fucoidans, laminarins, alginates, carrageenans, galactans, agar, porphyran, glucans and ulvans (Table 1). Some species of interest are Gigartina stellata (Stackhouse) Batters (Rhodophyceae); Himanthalia elongata (L.) S. F. Gray (Phaeophyceae); Monostroma nitidum Wittrock (Chlorophyceae); and the genus Laminaria spp. and Ulva spp. (Phaeophyceae and Chlorophyceae, respectively) -all of them with PS with a high water retention capacity. The last genus, Ulva, possesses a representative content of rhamnose, a water-soluble sulfated PS, representing an important moisturizing PS [36]. Most of the macroalgae-extracted PS have been applied for their skin-protective effects (anti-wrinkle, lightening, moisturizing, UV protective, antioxidant, anti-inflammatory, etc.) or for the physicochemical features that they provide to the product since their capacity to form hydrogels allow them to act as emulsifiers, stabilizers and viscosity controlling ingredients [38]. 
Table 1. Polysaccharides extracted from different macroalgae, and their properties and applications in the cosmetic field.

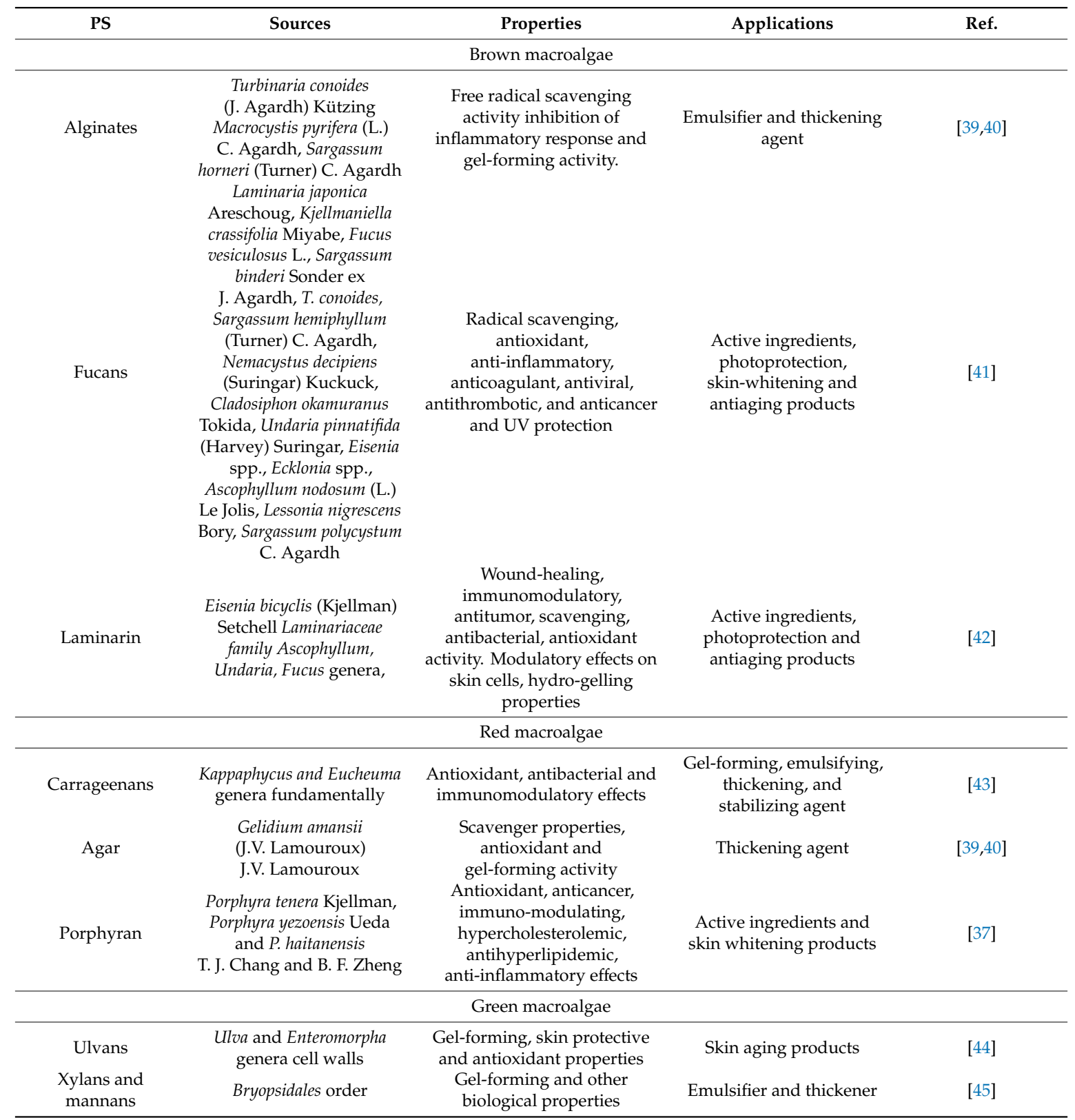

Agar is a gelatinous hydrocolloid, mostly obtained from agarophytes, such as Gracilaria spp. and Gelidium spp., belonging to red macroalgae. Agar has been widely applied in creams for its emulsifier and stabilizer properties and also has been demonstrated to be capable of controlling the moisture content in hand lotions, deodorants, foundation, exfoliant, scrub, cleanser, shaving cream, anti-aging treatments, facial moisturizer/lotion, liquid soap, acne treatments, body wash and facial powder $[39,40]$.

Alginates are formed from the alginic acid, a polymer of d-mannuronic and 1-guluronic acid, which can be obtained from various brown macroalgae, such as Laminaria digitata (Huds) J.V. Lamouroux. After the extraction of the alginic acid, it is stabilized using an alkaline solution and converted to a salt form. The most common salt is sodium alginate, which has been used as a gelling, viscosifying, or dispersion stabilizer agent $[39,40]$.

Carrageenans are linear sulfated PS extracted from red macroalgae, Rhodophyceae, such as those belonging to the genera Eucheuma, Chondrus and Gigartina, wfhere they are constituents of the cell 
walls. The name of these compounds seems to be originated in the region of Carragheen, on the south coast of Ireland, whose inhabitants used these red seaweed extracts for food and medicine more than 600 years ago [43]. Nowadays, they are widely used in the food and cosmetic industries as gelling, thickening and stabilizing agents. Their main application is related to proteins, due to their strong binding to them. The gelatinous extracts of the Chondrus crispus Stackhouse seaweed have been used as an additive for hundreds of years and, currently, they represent a vegan alternative to gelatin [23].

Fucoidan is a sulfated PS mainly composed of sulfate and fucose but, in its composition, it is also possible to find smaller amounts of monosaccharides, like glucose, galactose, mannose and xylose [46]. Fucoidans can be obtained from brown macroalgae from the Sargassum and Fucus genera and have been used as excipients $[47,48]$. Further research should be made to incorporate fucoidans as new active ingredients considering they have shown relevant bioactivities, like anti-coagulant and anti-inflammatory activities [49], skin whitening and photoprotection [50,51], as well as anti-hyaluronidase activity [52]. However, a study tested an ointment with 15\% fucoidan topically applied to rats at the doses of 50-150 mg/g, showing that fucoidan penetrated and was distributed into the skin, striated muscle, and plasma with linear pharmacokinetics [53]. Considering this, lower concentrations need to be tested to guarantee the effect is only local and does not deeply penetrate the skin, to be allowed in cosmetic formulations. Otherwise, with a systemic effect, it could only be used in pharmaceuticals [53].

Laminarin is a water-soluble PS consisting of $\beta-(1-3)$-glucan with $\beta-(1-6)$-linkages with a degree of polymerization around 25 that can be obtained from Laminaria spp., Saccharina spp. or Eisenia spp. [42]. Rich-laminarin extracts have demonstrated to have antioxidant and anti-microbial activities [54]. Besides, an in vivo assay using laminarin-based materials displayed wound healing activity, thus its topical administration may accelerate the healing process while protecting against oxidative and bacterial stress [42].

Porphyran, another sulfated PS, is present in the red macroalgae Porphyra spp., which have shown potential skin whitening, anti-inflammatory, antiulcer and analgesic properties [37]. Nowadays, new cosmeceutical products have been designed through the combination of macroalgae PS-based extracts, such as the commercially registered "Alguronic Acid", which has been used as an active anti-aging ingredient in skincare formulas [55-58].

\subsection{Proteins and Amino Acids}

The protein content in macroalgae is very variable and depends on the selected species, their placement and the period of collection. Nevertheless, seaweeds generally have high protein levels with a good profile of essential amino acids (AA). Proteins and AA extracted from macroalgae have been displayed to possess anti-inflammatory, antioxidant, anti-aging, anti-tumor and cytoprotective capacity, which convert them into useful ingredients for their application in cosmetics. The variability of the protein-based bioactivities is dependent on the AA composition and their sequence. Most of the AA act as moisturizing agents, but some macroalgae also have essential AA with antioxidant properties, and even AA that can modify physiological functions, showing antihypertensive capabilities since they can interact with target cells, inhibit enzymes and bind receptors [59].

Another group of compounds of macroalgae with great interest are the mycosporine-like amino acids (MAAs), which can be obtained both from micro- and macroalgae and can be used as sunscreen ingredients because they have a low molecular weight, are hydrosoluble and also stable molecules when exposed to light and heat $[37,55,56]$. Arginine is also an AA of interest because it is a precursor of urea, a component of the natural moisturizing factors (NMF) that is used in cosmetic formulations and can be obtained from red macroalgae genera like Palmaria and Porphyra. Other macroalgae have been described to act through other pathways, such as the extracts obtained from the brown macroalgae Alaria esculenta (L.) Greville, which induce a significant decline in the amount of progerin in aged fibroblasts producing an anti-aging effect. 


\subsection{Lipids}

Generally, lipids are used in cosmetics as emollients and specific ingredients for skincare and skin treatments, haircare and make-up or decorative products, being the most commons triglycerides, emulsifiers, waxes and structured lipids [60]. The amount of lipids found in macroalgae is usually lower than in terrestrial plants. However, algae possess a wide variety of lipids from fatty acids, triglycerides, phospholipids, glycolipids and sterols to some liposoluble vitamins (A, D, E and K) [13]. Among the properties of the lipids, they have anti-allergic, antioxidant and anti-inflammatory effects (Table 2). Macroalgae-based lipids have been mostly used in cosmetics to prevent skin water loss. This is the case of $\omega-6$ polyunsaturated fatty acids and especially the C- 18 fatty acids. These compounds can be obtained from different seaweeds, such as Laminaria spp., which are broadly applied as a moisturizer [55,56].

Table 2. Macroalgae lipids and lipophilic molecules and their use in cosmetics. The three main groups of macroalgae possess representative species able of synthesizing different lipophilic molecules that have been demonstrated to have diverse bioactivities with application in the cosmetic industry [23,61-64].

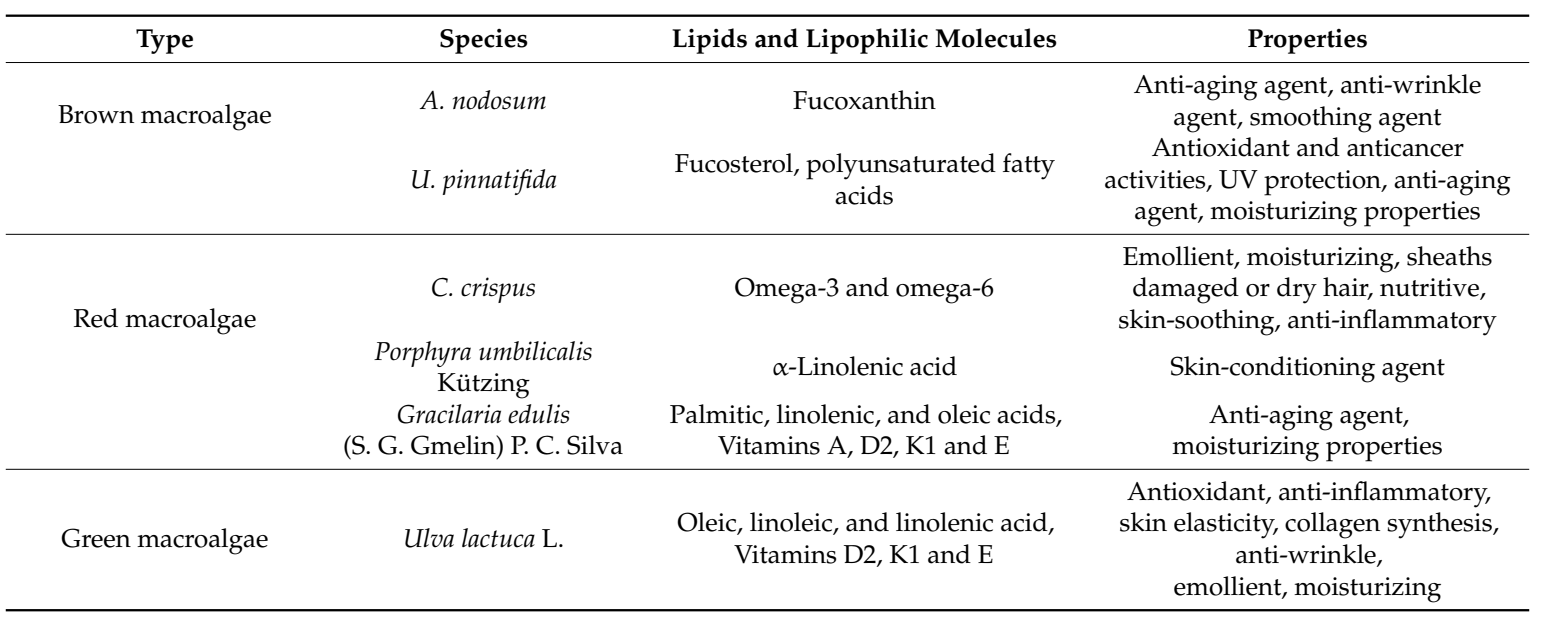

Extracts from the red macroalgae P. umbilicalis, in combination with liposoluble vitamins (A and E), have shown great results at significantly improving the performance of sunscreens. The formulation tested helped preventing inflammation and UV-induced DNA damage, thus being considered a promising blend to produce an even more effective sunscreen formulation with anti-aging properties [65]. Extracts of Laminaria spp. can be an ingredient of choice to formulate products, avoiding excessive water loss and providing moisturizing activity. Several brown macroalgae can be used with this intent due to their high content in natural moisturizing factors, ceramides and aquoporins $[23,66]$. Algae like $U$. pinnatifida are also of great interest because they are rich in polyunsaturated fatty acids that help to reconstruct the intercellular cement, reinforcing the skin barrier. Linoleic acid is one of the most effective $\omega-6$ polyunsaturated fatty acids present in brown macroalgae, helping to restore the transepidermal water loss and bring it back to normal values. Other essential fatty acids that also have this ability are linoleic acid and $\gamma$-linolenic acid [23]. In addition, other compounds like fucosterol extracted from brown macroalgae can reduce skin photoaging by reducing matrix metalloproteinase expression and increasing procollagen synthesis, thus being a good start for the development of new anti-aging and skin-protective formulations based on macroalgae compounds [61].

\subsection{Pigments}

As exposed in the introduction, macroalgae are photosynthetic organisms with a high content of pigments that absorb light to nourish themselves in an autotrophic way. Macroalgae are capable of synthesizing up to three types of pigments: chlorophylls, carotenoids (comprise carotenes and xanthophylls) and phycobiliproteins [67]. The type of pigments synthesized by each macroalgae class 
defines its color, also depending on the habitat and the intensity of light available, determined by the depth at which they are found [68].

Natural colorants have a better reputation and acceptance among consumers than the artificial ones, which are related to negative side effects for human health and the environment. Therefore, macroalgae are an attractive source of natural pigments, since they may provide coloration to cosmetic formulations and they possess biological properties that revalue their use [69].

Chlorophylls and carotenoids correspond to lipophilic molecules, thus they require organic solvents, such as methanol, acetone or dimethyl sulfoxide, for their extraction; in turn, phycobiliproteins are polar molecules for which polar solvents like water may help to recover them.

\subsubsection{Phycobiliproteins}

This type of compound is present in macroalgae, mostly red macroalgae, as part of a supramolecular complex called phycobilisomes that participates in photosynthesis. The phycobiliproteins can be found in species such as Porphyra spp. or Gracilaria gracilis (Stackhouse) Steentoft, Irvine and Farnham. In this last one, three different phycobiliproteins have been detected, in decreasing concentrations, as follows: R-phycoerythrin, phycocyanin and allophycocyanin. These pigments have been used in cosmetics as natural ingredients and represent an alternative to reduce the use of synthetic colorants [13,70-73]. Besides, different bioactivities have been related to the group of phycobiliproteins: hepato-protective, antioxidant, anti-diabetic, anti-hypertensive, immune-modulator, anti-inflammatory, anti-aging and may also have a preventive role in degenerative diseases, such as Alzheimer's or cancer [74,75].

The production of the phycobiliproteins can be regulated by modifying the culture conditions, such as the nutrient availability and physicochemical parameters (light, temperature, water, $\mathrm{pH}$, etc.) [72]. The use of phycobiliproteins in cosmetics is remarkable since they remain stable in solutions with $\mathrm{pH}$ ranges between 5 and 9. Among them, phycoerythrin has shown more stability during its conservation than phycocyanin, and even more than chlorophylls and carotenoids. Therefore, phycobiliproteins represent an alternative ingredient for their application in cosmetics in products mainly utilized as dyes, such as eye shadows, makeup, creams or lipsticks $[23,76]$.

\subsubsection{Carotenoids}

Carotenoids are isoprene derivatives with well-recognized antioxidant properties; in fact, when macroalgae are exposed to excessive UV radiation, an increase in the synthesis of these pigments has been observed. Therefore, the capability of carotenoids to mitigate the harmful effects of UV radiation has been exploited for its application in cosmetic formulations as preservatives with photoprotective, antioxidant or anti-aging properties [77]. The most representative carotenoids for the cosmetic industry are astaxanthin, zeaxanthin, $\beta$-carotene and fucoxanthin.

The xanthophyll, astaxanthin, has displayed antioxidant capacities superior to those of $\alpha$-tocopherol, being able to prevent skin damage caused by UV radiation, as well as to decrease the advance of macular degeneration associated with age [6]. The zeaxanthin present in green and red macroalgae has demonstrated to present anti-tyrosinase activity, an enzyme related to the production of melanin. The inhibition effect of zeaxanthin on this enzyme may prevent the formation of skin spots, which point to the use of this pigment as a whitening agent $[23,67,77]$. $\beta$-carotene, one of the main carotenoid pigments, is known for its powerful antioxidant properties and presents provitamin A activity, so it has been applied as an anti-aging ingredient [6]. Fucoxanthin, responsible for most of the pigmentation of brown macroalgae, has been described to protect against oxidation processes through a reduction of the radical oxygen species (ROS) formation induced by UV radiation. Additionally, fucoxanthin reduces matrix metalloproteases (MMPs) expression, specifically, MMP13-related to tumor processes-as well as reduces tyrosinase activity. Thus, it has been stated that the oral and/or cutaneous administration of fucoxanthin may inhibit the mRNA expression related to melanogenesis $[23,67]$. 


\subsubsection{Chlorophylls}

Chlorophylls constitute the most widespread group of pigments in the Plantae kingdom. Chlorophylls and their derivatives, characterized for containing a porphyrin ring, are present in all photosynthetic organisms, including macroalgae. However, the proportion in which they are found is very variable, since green macroalgae owe their color to the predominance of chlorophylls of the series $a$ and $b$; the brown ones contain chlorophylls $a$ and $c$ together with carotenoids, especially $\beta$-carotene and fucoxanthin; and red seaweed show said pigmentation due to the presence of phycobilins, which can be red (phycoerythrins) or blue (phycocyanins and allophycocyanins), although they also contain chlorophylls of the series $a$ and $d$ [67]. Chlorophylls possess interesting antioxidant properties; however, their useful life is relatively short when exposed to light or excessive storage temperatures that destabilize the molecule, causing a loss of color and antioxidant capacity. Nonetheless, some derivatives, such as pheophytin $a$ and pheophorbide $a$, present in macroalgae, have recently attracted the attention of the scientific and cosmetic industrial communities due to their antioxidant bioactivity, which gives them the capacity to be used in the food, cosmetic and pharmaceutical industries [78]. As is the case for carotenoid content, the amount of chlorophyll in the macroalgae is also increased after overexposure to UV radiation, for photoprotective purposes [77].

\subsection{Phytohormones}

This category of metabolites includes a group of unrelated chemical compounds, such as auxins, cytokinins and betaines, among others. Phytohormones with identical structures have been identified in high plants and macroalgae species. Their physiological role in macroalgae has still not been well defined; however, it seems to be similar to their role in higher plants. Thus, phytohormones in macroalgae may be involved in growth and development regulation and the response to environmental stress factors [79,80]. In macroalgae, extracts obtained from Monostroma oxyspermum (Kützing) Doty and Ulva spp. have been characterized using liquid chromatography. In terms of phytohormones, different structures have been identified, such as abscisic, gibberellic, salicylic, nature-3-acetic and nature-3-butyric acids, as well as kinetin riboside [13,41]. The mechanism of action of phytohormones in cosmetical products has not been totally clarified and requires further studies to be fully disclosed. Nevertheless, some studies have pointed to phytohormones as an anti-age ingredient that may be considered to be included in skincare cosmetics $[79,81]$.

\subsection{Terpenoids and Halogenated Compounds}

Macroalgae also contain other types of compounds that show bioactivities, such as alkaloids, terpenoids or halogenated compounds, related to antibacterial, antioxidant, anti-inflammatory and antitumor properties. Thus, it may be interesting to consider their use in the cosmetics, cosmeceutical, food and/or pharmaceutical industries. A good example of their application may be the chromene meroterpenoid tetraprenyltoluquinol, obtained from the brown macroalgae Sargassum muticum (Yendo) Fensholt. This molecule showed its ability to reduce the production of ROS by $21 \%$. This means that it possesses anti-photooxidative stress activity that may protect human dermal fibroblasts from ROS damage. Likewise, spatane diterpinoids synthesized by the brown seaweed Stoechospermum marginatum (C. Agardh) Kützing have effective anti-tumor capacity against the growth of malignant melanomas, so its use in creams, sunscreens and other formulations could be considered [67].

Regarding the halogenated compounds, their content in macroalgae undergoes strong variations, depending on the selected species and the treatment they received during both the harvest and the processing stages. Fucus spp. and Laminaria spp. contain important amounts of iodine, which can reach up to $0.9 \%$ of the dry weight. Iodine has the property of promoting lipolysis through its effect on thyroid metabolism, which increases the entry of fatty acids into the mitochondria. Hence this compound has resulted in an important ingredient at the cosmetic, food and pharmacological level [23]. Likewise, there are other halogenated compounds, derived from bromine (bromoform and dibromoacetic 
acid) synthesized by some macroalgae, such as the invasive species Asparagopsis armata Harvey (Rhodophyceae), which are related to powerful antimicrobial properties [82]. Nevertheless, not all the bio-compounds found in macroalgae can be aimed at human consumption or topical application. That is the case of pachydictyol A, a diterpene alcohol produced by the brown seaweed Pachydictyon coriaceum (Holmes) Okamura, which cannot be used in the preparation of cosmetic formulations due to its high cytotoxicity action [23]. Therefore, despite the hopeful finding of new bioactive compounds, not all are suitable for use in cosmetics; numerous and previous tests are necessary to determine their effectiveness and safety.

\subsection{Phenolic Compounds: Polyphenols and Phlorotannins}

Phenolic compounds are secondary metabolites produced by macroalgae; thus, they are not essential, and therefore not involved in the main physiological processes, such as reproduction or nutrition. However, they have an important role in the organism's survival and the interaction with the media since they are synthesized in response to environmental factors for its protection and adaptation. Therefore, the same species cultured under different conditions display variable concentrations of secondary metabolites, such as the phenolic compounds [83-86]. Polyphenols are polymers of a simple unit (phenol) that comprise an aromatic ring with hydroxyl substitutions directly responsible for their antioxidant capacity. Based on the environmental stimuli that subdue the organism, such as excessive UV radiation, different polyphenols will be synthesized and, depending on the final product, they can follow two different metabolic routes: the shikimic acid or acetate-malonate pathways [41]. The number of phenolic units determines the physicochemical characteristics and bioactivities of each polyphenol and permits to classify them. In macroalgae, the most relevant phenolic compounds are the phlorotannins, whose simplest structural unit is phloroglucinol [67]. This group is exclusively produced by macroalgae, especially by brown macroalgae [32], such as Ecklonia cava Kjellman, which biosynthesize phlorotannins, such as eckstolonol. This molecule has been described to possess excellent antioxidant and photoprotective properties. Eckstolonol has been demonstrated to reduce the excessive production of ROS induced by excessive UV exposure. It triggers an increment in the enzymatic activity of the catalase and superoxide dismutase that, in the last term, protects against the effects of UV radiation. Eckstolonol has also shown a capacity for decreasing the levels of proteins and pro-apoptotic factors p53, Bax and caspases 3 and 9, while favoring an increase in the levels of the anti-apoptotic protein $\mathrm{Bcl}-2$, which convert this group of molecules into extremely attractive compounds for their use in anticancer therapies [67]. M. pyrifera is another brown alga that contains other phlorotannins, such as phloroeckol and tetrameric phloroglucinol, substances that showed anti-diabetic properties and, in addition to the antioxidants ones, properties that can be useful in preventing skin aging [77]. Likewise, benzoic and cinnamic acids, flavonoids and phlorotannins have also been identified as bioactive compounds in brown macroalgae extracts [32].

Moreover, phlorotannins are also present in other groups of macroalgae, as evidenced by a study in Corallina pilulifera Postels and Ruprecht-a red macroalgae from which an extract rich in phenolic compounds and phlorotannins was obtained. This extract was capable of inhibiting the MMP overexpression, caused by UV exposure, which has been related to the prevention of the premature degradation of collagen, wrinkle formation and the appearance of cancer cells. These properties make phlorotannins an excellent ingredient for photoprotective preparations [6]. Additionally, some of these compounds, such as phlorofucofuroeckol A, diphlorethohydroxycarmalol, eckol, dioxynodehydroeckol, dieckol and phloroglucinol, also exhibited inhibitory action of the tyrosinase enzyme, reinforcing its use as a sunscreen [67]. Other actions associated with phenolic compounds in general, and phlorotannins in particular, are anticoagulant, antiviral, immune-modulatory, antimicrobial and anti-inflammatory activities. All these bio-capacities reveal phlorotannins as compounds with potential for their inclusion in nutraceutical, pharmaceutical and cosmeceutical products [32]. Currently, phenolic compounds extracted from other types of natural plant matrices, such as Rosa $x$ damascena Mill. or Dracocephalum 
moldavica L., seek to replace the synthetic ingredients and preservatives associated with health damage [69].

\subsection{Vitamins}

Most vitamins are lipophilic compounds, known for their high antioxidant power. Interestingly, the vitamins that have been synthesized artificially have a lower antioxidant capacity than those extracted from natural matrices. Hence, new and alternative natural sources of vitamins have been investigated, such as macroalgae [87]. Although vitamin-rich extracts from macroalgae are mostly obtained from microalgae, few studies have confirmed their presence in macroalgae, such as those belonging to the genus Phorphyra. Specifically, the red macroalgae P. umbilicalis, whose extract has been used to prepare sunscreens; this due to its protective effects against DNA damage as well as its ability to favor cell renewal. This extract was also described to be rich in vitamins A and E. Thus, extracts from P. umbilicalis are a promising source of ingredients for the cosmetic industry, on its own, or in combination with other beneficial extracts, such as those from ginseng [6].

Vitamins have also been found as part of the brown macroalgae composition, along with minerals and essential fatty acids. All these compounds have been associated with the regeneration of the skin at the cellular level, favoring its protection against aging [77]. A summary of the main molecules extracted from macroalgae (non-polysaccharides or lipids) with applications in the cosmetic industry is shown in Table 3.

Table 3. Non-polysaccharide or lipid molecules present in macroalgae with applications in the cosmetic industry.

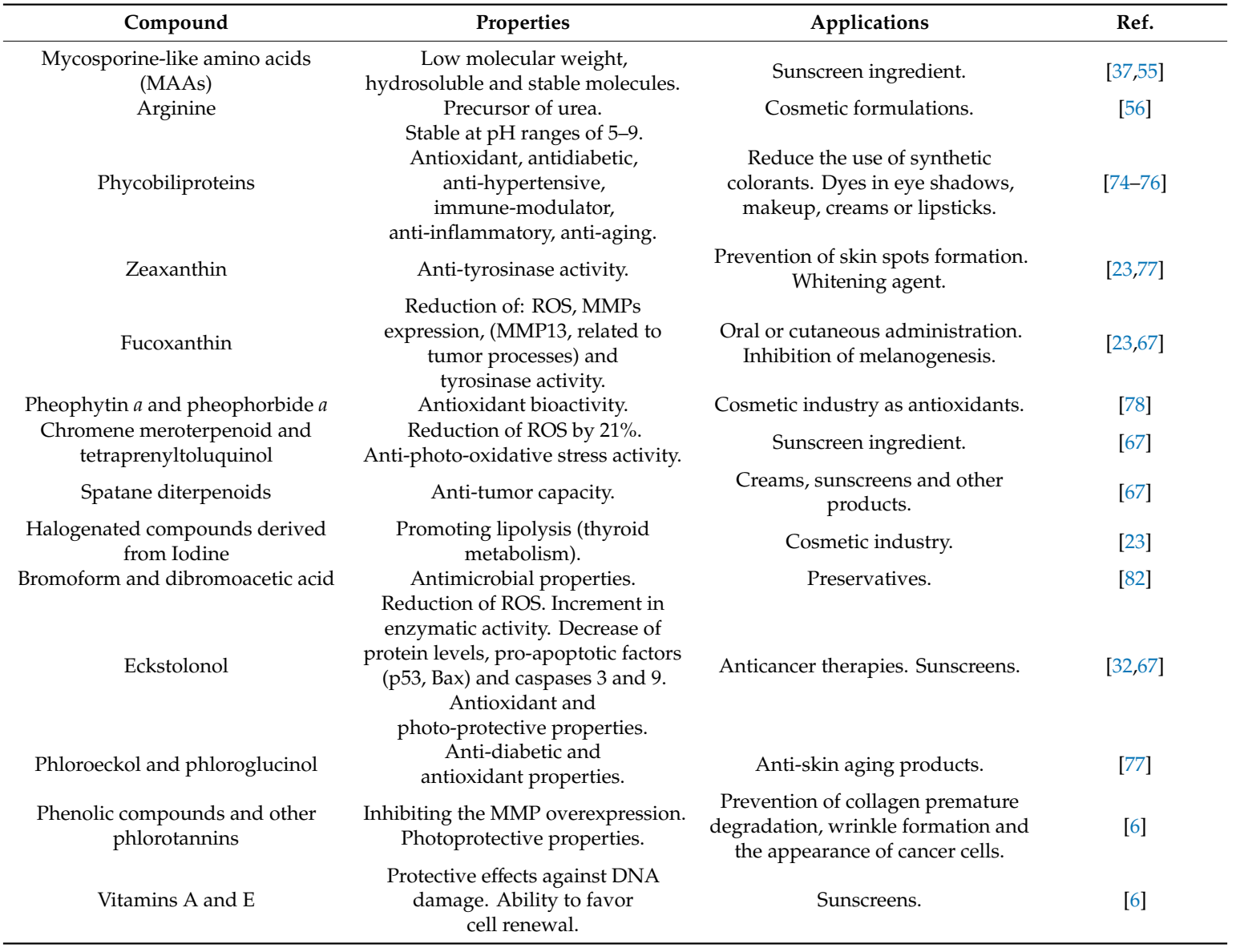




\section{Macroalgae Applications in Cosmetics}

\subsection{Active Ingredients}

As the cosmetic industry has advanced and evolved, cosmetic ingredients have undergone adaptations and evaluations through scientific and technological research works that endorse their current use and recognize their value and beneficial application. Active ingredients have been tested both on in vitro and in vivo models to ensure their efficacy and safety, before being accepted as ingredients in the cosmetic industry, which constantly presents new innovative options to stay up to date with the new skin product trends in the market [88]. A correctly formulated cosmetic product designed to fit a specific skin type can have many positive effects on hydration and stabilization of the epidermis. To achieve this aim, the formulator should take into account the main aspects, such as the interaction between the skin, carrier and active ingredients, which will influence the release and enhance the performance of the last one [88]. The development of this personalized and active cosmetics is currently demanded by consumers who expect cosmetic products with active ingredients to have pharmaceutical and therapeutically benefits, such as antioxidant or anti-inflammatory effects, so the term cosmeceutical has been introduced.

Algae are of great interest to the cosmetic industry for various reasons, not only as a source of polysaccharides, minerals, lipids and proteins, but also because they produce a wide variety of secondary metabolites, such as phenolic compounds, terpenes, halogen compounds, carotenoids, vitamins and sulfur and nitrogen derivatives [23]. These compounds present in macroalgae and their related bioactivities have been extensively studied. Some isolated molecules of brown macroalgae, for example, demonstrated anti-aging, anti-photoaging, lipolytic and skin lightening (whitening) effects, while red seaweed results have shown anti-aging, anti-photoaging, anti-UV and antioxidant activities [13]. Thus, the biological activities of the molecules found in macroalgae can be explored to be used as new ingredients with several relevant properties for the cosmetic and personal care industries. Studies that confirm their capacities are necessary to provide new molecules that fill customer-based cosmetic claims and to describe the effects of the final product. Results from these studies are aimed to be applied for marketing and advertising purposes, showing the properties of the improved product to the consumers that should make items more appealing and, thus, implement their sell.

Antioxidants are a very well-known group of molecules used as active ingredients that have been added to a large number of cosmetic formulations to provide properties such as anti-aging or prevent free radicals formation caused by UV exposure, as well as being anti-wrinkle. These highly active compounds significantly delay or inhibit the reaction chain of oxidation, even when used at low concentrations. Nevertheless, formulations have shown many stability problems associated, mostly because these substances undergo degradation processes when exposed to stress conditions like $\mathrm{pH}$, light and temperature. This degradation during storage diminishes the shelf life and can result in a reduction or loss of the activity and effectiveness of the ingredient [89]. Considering that cosmetic and cosmeceutical products represent a daily product for an important part of society, consumers expect a large variety of options with high efficacy. Thus, the evaluation and improvement of the stability of natural ingredients in the future matrix are crucial for their further inclusion and application. Hence, good and stable formulations are of great importance and economic interest. Furthermore, an increasing concern by the consumers in safer skincare products and environmentally friendly ingredients has arisen in the last decades. This trend has been prompted for diverse reasons, such as the negative impact of the use of synthetic compounds, both in personal care as well as in ecosystems and organisms. While plant cosmetics have always been used, macroalgae represent a new and exciting raw material with promising results and effective benefits for skin treatments, with fewer side effects and a growing interest from informed consumers [90]. Therefore, a market based on natural products obtained from vegetable matrices like macroalgae seems to be a good investment considering that many macroalgae species containing bioactive molecules are considered invasive. This approach 
would be doubly eco-friendly since invasive species would be removed from coasts and estuaries to preserve the ecosystems and they would be exploited for the extraction of compounds of interest.

Lastly, nutricosmetics are a new trend in skincare that joins food, cosmetics and pharmaceuticals in one field and involves the consumption of supplements to improve and maintain skin health. These supplements comprise many micronutrients like vitamins, minerals and amino acids, and especially point to skin, hair and nail care. Nowadays, cosmetic industries are also focused on producing these supplements with a high content in different ingredients, such as collagen, hyaluronic acid, vitamins C and E, elastin and other molecules [91]. Macroalgae could be used as the raw materials to obtain these new nutricosmetics.

\subsection{Excipients, Gelling and Thickening Agents}

Excipients are inactive but indispensable substances used in cosmetic formulations to enhance a product's long-term stability and microbial resistance to contamination, or to optimize the active ingredient's delivery. Although many synthetic molecules are used as excipients, the use of macroalgae-derived compounds has many advantages as they have a simple extraction and purification process, are biodegradable and biocompatible, as well as easily available, making them a cheaper and more natural alternative; thus, marine macroalgae are a great matrix for the extraction of these useful molecules [92].

Carrageenans are polyholosides, specifically d-galactans, with a variable content of sulfated functional groups that can be obtained from red macroalgae of the Kappaphycus and Eucheuma genus. A common pattern found in carrageenans is the alternation of the $\alpha(1 \rightarrow 3)$ and $\beta(1 \rightarrow 4)$ bonds between the residues of d-galactose [93]. The number and the position of the sulfated groups in the carrageenans modify their solubility. The gelling capacity of the carrageenans derives from its ability to form single and double helices, the latter being stabilized by hydrogen bonds. The presence of galactose-6-sulfate and galactose-2, 6-disulfate allows the formation of a three-dimensional network. This structure breaks the stereoregularity of the chain, forcing it to bend, and forming a pattern with double helixes combined to several neighbor chains. These associations are limited because of the electrostatic repulsion that generates a stable scaffold and an elastic gel. The gelation capacity depends on the presence of a divalent cation, such as $\mathrm{Mg}^{2+}, \mathrm{Ca}^{2+}$ or $\mathrm{Sr}^{2+}$ [94]. Based on the number of sulfated groups and their position in the molecule, carrageenans can be classified under four classes, called $\kappa, l, \lambda$ and $\mu$. The group of $\lambda$-carrageenates is mostly used as thickening agents and the $\iota$-carrageenates as gelling agents. Carrageenans can be commonly and traditionally found among the ingredients of dental care and oral formulations, like toothpaste. More than 20 years ago, the potential of carrageenans was already stated based on their interesting psychosensory and moisturizing properties [95]. Indeed, since then the application of the carrageenans have evolved and have reached the food industry where they are used to improve the texture of different matrixes (dairy and meat-based products); as pharmaceutical excipients for preventing the degradation of the drug and provide a controlled delivery; and as a cosmetic ingredient in creams, air freshener gels, shampoo or shoe polish. Nevertheless, despite their currently wide utilization, the physicochemical properties and bioactivities of natural carrageenans are still under study in order to provide new applications for their use in different formulations and the development of innovative products [96].

Alginate is also a relevant matrix on this subject because of its rheological properties, such as gelling, viscosifying and stabilization of dispersions [39,40]. Alginate can be obtained from brown marine macroalgae like A. nodosum, Laminaria hyperborea (Gunnerus) Foslie and L. digitata. This polysaccharide represents a useful ingredient for the pharmaceutical industry since it can be used for embedding drugs that prevents their degradation and provides their controlled release. The utilization of alginate as a matrix has been further extended due to its stability at a $\mathrm{pH}$ higher than 3-4. Hence, its bioadhesive and stability properties have been applied for the formulation of the microencapsulating materials employed for drug delivery systems and innovative cosmetic formulations [47]. 
As explained before, agar is a marine PS found in the cell wall of red macroalgae like Gelidium and Gracilaria species, and it is mainly formed by linear agarose and heterogeneous agaropectin. This compound is used as a gelling agent, but also as an emulsifying and suspending agent [97]. Besides, several in vivo studies throughout the years showed that agar beads are a great dispersing agent and a great vehicle for sustained-release preparations [98-100].

Another interesting PS extracted from marine brown macroalgae, such as Sargassum stenophyllum C. Martius and F. vesiculosus, is fucoidan [47]. This sulfated PS composed of fucose and minor monosaccharides has been successfully applied as a drug carrier, being a wall component of microparticles, nanoparticles, hydrogels and even multilayer nanocapsules, with immense potential to be used in controlled release systems for the diverse bioactive compounds for skin formulations $[46,48,92,101]$.

\subsection{Additives}

An additive is an ingredient intended to improve the product preservation or its organoleptic properties; for example, preservatives, colorants or fragrances [59]. Some of these additives have been considered in the Regulation (EC) No 1223/2009 of the European Parliament and of the Council of 30 November 2009 on cosmetic products. This regulation has established the definition of different concepts, such as a preservative or colorant, among many others, to ensure the functioning of the internal market and a high level of protection of human health. Prohibited substances are indexed in the Annex II while Annex IV and V compile all the colorants and preservatives allowed in cosmetic products, respectively [102].

\subsubsection{Preservatives}

The term preservative has been described by the Regulation (EC) No 1223/2009 as a substance that is exclusively or mainly intended to inhibit the development of micro-organisms in a cosmetic product [102]. From this definition, understandably, the use of these compounds implies also the extension of the life of the product and, of course, the protection of the health consumer. Annex $\mathrm{V}$ enumerates the preservatives permitted to use in this kind of product [102]. Few additional compounds that prevent chemical degradation by the oxidation (due to the presence of oxygen) or photooxidation processes (caused by UV-light exposure), such as the antioxidants DL- $\alpha$-tocopherol acetate (Toco), butylated hydroxyanisole (BHA) and butylated hydroxytoluene (BHT), are commonly added to the cosmetic formulations. As they are not strictly considered preservatives, they are not included in the Annex V of the EC 1223/2009. However, these compounds are usually taken into consideration when cosmetics are chemically characterized or analyzed $[103,104]$. Nowadays, the presence of some of these chemical products, considered or not as strictly preservatives, has been demonstrated to represent a threat to human health, causing hypersensitivities and allergies, among others [105-108]. For a few years, the trend in cosmetics was to use natural self-preserving substances. Preservatives included in Annex V of the EC 1223/2009 were replaced by other ingredients not listed, which can minimize the adverse side-effects while they keep their antimicrobial or antioxidant properties [109]. Essential oils are a good example of self-preserving compounds in cosmetics [110,111]. Nowadays, the use of natural ingredients, such as those extracted from macroalgae, has demonstrated to act as (self-)preserving substances. Extracts from the green macroalgae $U$. lactuca, which contains as major compounds two types of chlorophyll ( $a$ and $b$ ) and three main groups of carotenes (9-cis $\beta-, \alpha-$ and all-trans $\beta$-carotene), were demonstrated to possess an antioxidant activity comparable to Toco, BHA or BHT. Additionally, U. latuca extracts exhibited antimicrobial potential against Gram-positive (Bacillus subtilis, B. cereus, B. mycoides, Staphylococcus aureus and Micrococcus luteus) and Gram-negative bacteria (Klebsiella pneumoniae and Serratia marcescencs) even though their anti-fungal activity was weaker $[112,113]$. Another species from the same genera, Ulva pertusa Kjellman, together with Dictyota coriacea (Holmes) I.K. Wang, Hy. S. Kim and W.J. Lee (Phaeophyceae) showed antioxidant and antimicrobial activities when used in a lip balm [114]. A broad study about the antimicrobial activity 
of multiple Iberian macroalgae species collected at different seasons pointed to Phaeophyceae as the most active taxa, followed by Rhodophyceae and Chlorophyceae, and autumn followed by spring as the seasons with more active taxa. Although, Rhodophyceae was demonstrated to be the one with the highest values and the broadest spectrum of bioactivity. Colpomenia spp., Cystoseira spp. and Padina spp., belonging to Phaeophyceae, displayed antimicrobial activity against Gram-positive bacteria (Bacillus subtilis, B. cereus and Staphylococcus aureus). On the other hand, the red macroalgae A. armata, Bonnemaisonia asparagoides (Woodward) C. Agardh, Bonnemaisonia hamifera Hariot and Falkenbergia rufolanosa (Harvey) F. Schmitz showed antimicrobial activity for the same Gram-positive bacteria with additional properties against Gram-negative bacteria (Escherichia coli and Pseudomonas aeruginosa) and fungi (Candida albicans) [115].

\subsubsection{Dyes and Pigments}

Colorant has been defined by the EC No $1223 / 2009$ as a substance exclusively or mainly intended to color the cosmetic product, the body as a whole or certain parts thereof, by absorption or reflection of visible light and it also includes precursors of oxidative hair colorants. The Annex IV of this regulation enumerates the list of permitted colorants in cosmetic products [102]. However, along the years, few amends have been made to the EC No 1223/2009, about colorants and dyes. After the publication of a scientific article that associated the use of permanent hair dyes and bladder cancer, a few amendments were published [116]. Most of the amendments related to colorants and involved several chemical compounds from hair and eyelash dyes. These amendments included some concentration modifications of a few synthetic substances and recommendations established to reduce health threats [117-119]. Besides, punctual cases of allergy, sensitization or toxicity, due to the use of cosmetic products, such as nail polish, eye shadow, permanent make-up or hair dyes, have been described throughout the scientific literature [120-123]. Therefore, the use of natural colorants and dyes in cosmetics is intended to avoid adverse health effects. Macroalgae have been demonstrated to represent a varied source of pigments. Phycoerythrin is a red pigment that can be extracted from different types of macroalgae, being mostly found in red ones (Rhodophyta); it has been detected in Mastocarpus stellatus (Stackhouse) Guiry, Palmaria palmata L., Gelidium pusillum (Stackhouse) Le Jolis, Agardhiella subulata (C.Agardh) Kraft and M. J. Wynne, Gracilariopsis longissima (S. G. Gmelin) Steentoft, L. M. Irvine and Farnham, Gracilaria vermiculophylla (Ohmi) Papenfuss, Polysiphonia morrowii Harvey and Pyropia elongata (Kylin) Neefus and J. Brodie [124-126]. As explained above, this class of pigments has great potential applications, for instance R-phycoerythrin has been demonstrated to possess diverse biological activities: antitumor, antioxidant, immunosuppressive or hypertensive [127,128]. Beta-carotene is a yellow pigment known to be also a precursor to vitamin A and, thus, considered a free radical scavenger and antioxidant [129]. Together with beta-carotene, few other carotenoids, such as fucoxanthin or chlorophylls, have been extracted from brown macroalgae, such as Laminaria spp. and U. pinnatifida; from red macroalgae, like Corallina elongata J. Ellis and Solander and Jania rubens (L.) J.V. Lamouroux; or from green alga, U. lactuca [112,130].

\subsubsection{Aromas and Fragrances}

Nowadays, most of the cosmetic products contain aroma, fragrance or perfume. However, these additives, usually synthetic ones, are a source of sensitization, allergies or dermatitis [131,132]. The use of natural fragrances can reduce the number of these adverse cases. Even though macroalgae has not been underlined as a very common source of aromas, some authors have already studied the volatile compounds found in the green alga, Capsosiphon fulvescens (C. Agardh) Setchell and N.L. Gardner, and the brown alga, Fucus serratus L. [133]. The most relevant application of macroalgae in this area may be to formulate walls aimed for microcapsules. The main purpose of the microencapsulation is to protect and control the release of a target molecule; however, sometimes the target molecules may have bad odors, and therefore microencapsulation using a macroalgae extract may provide a physical barrier to mask bad odors. 


\section{Product Applications}

\subsection{Sunscreens: Photoprotection and Anti-Photoaging}

Sunscreen comprises a category of cosmetic products capable of absorbing or reflecting UV radiation to prevent sunburn. The EC No 1223/2009 refers to UV-filters and defines them as substances that are exclusively or mainly intended to protect the skin against certain UV radiation by absorbing, reflecting or scattering UV radiation [102]. Sunscreens are aimed to prevent the collagen degradation that causes photoaging and wrinkle formation. Medical research has demonstrated that these mechanisms are induced by MMP-1 expression [134]. Excessive UVA radiation stimulates the transcription of the activator protein 1 (AP-1), which activates the MMPs, a family of enzymes capable of digesting the extracellular matrix components, including collagens IA1 and IA2, fibronectin, laminin and proteoglycans, accelerating the skin aging and wrinkle formation $[6,23,26,135]$. Hence, agents that stimulate collagen synthesis and preferably inhibit the photo-induced upregulation of MMPs are considered beneficial ingredients in cosmetically active skin-care products to provide a double anti-aging and photoprotective effect [31]. Specific macroalgae extracts and molecules with capacity for inhibiting MMPs or stimulating collagen or keratin synthesis are enumerated in the subsequent sections. Macroalgae are a well-known source of compounds with UV-filter activity. Many species have been described as photoprotective due to their high content in different compounds, such as (a) phenolic compounds from the brown macroalga Halidrys siliquosa (L.) Lyngbye [136] and the red one C. pilulifera [137]; phlorotannins from both the brown macroalgae E. cava, A. nodosum and Macrocystis integrifolia Bory [138-140]; or other diverse compounds, such as fucoxanthin or sargachromenol, extracted from diverse species of Sargassum [141-143]. As previously cited, MAAs is a group of secondary metabolites produced by different types of organisms, known for their capability to absorb UV radiation in the harmful range from 309 to $362 \mathrm{~nm}$ [144]. These compounds have been found in red macroalgae P. umbilicalis, Porphyra rosengurttii J. Coll and J. Cox, P. palmata, Gracilaria cornea J. Agardh, Gelidium corneum (Hudson) J.V. Lamouroux and Ahnfeltiopsis devoniensis (Greville) P. C. Silva and DeCew [145]. Furthermore, a study investigating fucoidans derived from Sargassum confusum determined that the UVB-protective effects in human keratinocytes were very promising with a dose-dependent reduction in intracellular ROS levels while recovering the cell viability. This results suggest that these compounds can be a useful cosmetic ingredients [51].

\subsection{Moisturizers}

The skin is the natural barrier of the human being against harmful environmental factors. The lack of hydration and moisturizing triggers the natural skin process of wrinkling but also may damage its structure with the occurrence of eczema, for example, which reduces its capacity of protection. The high percentage of water content in the epidermis is due to NMF, which are hygroscopic compounds, such as corneocytes (anucleated cells filled with keratin filaments), amino acids, urea, sugar or minerals, among others $[59,64,146]$. To protect skin health and prevent its damage, moisturizers are commonly used to maintain hydration. Along with water and hyaluronic acid, PS represent an important ingredient to hydrate and moisturize the skin. As described, PS are polymers of monosaccharides that may get hydrated into an aqueous environment, becoming a hydrogel or hydrocolloid. This structure is considered a biodegradable biopolymer. Macroalgae represent an economic, biodegradable and non-toxic source of these natural moisturizers (alginate, agar, carrageenan or fucoidans). Fucoidans isolated from F. vesiculosus have shown to present a concentration-dependent inhibition of the hyaluronidase enzyme with an IC50 of $2.9 \mu \mathrm{g} / \mathrm{mL}$, which is linked to the prevention of tissues damage [147]. Brown macroalgae are recognized as a good source of alginates [148], such as L. japonica, whose content in hygroscopic substances and proteins displayed the ability to reinforce the NMF in the skin and to create a protective barrier $[59,149]$. Other species from the same genus considered as a good source of high-quality alginates are L. hyperborea and L. digitata [148]. Extracts from another brown macroalgae genus, L. japonica, were shown to have a better moisturizer capacity than 
the hyaluronic acid [59]. PS, among other substances, obtained from the brown alga S. horneri were compared to that from the red alga P. yezoensis in terms of moisturizing capacity. The brown one displayed higher moisture retention than the red one [150]. However, red macroalgae are still well-considered in the cosmetic industry for their rich content in protein and have a good aminoacidic profile. Few AA obtained from species belonging to the Palmaria and Porphyra genera have been used in cosmetic products. These genera possess a high concentration of arginine, which is a precursor of urea, and considered one of the components of the NMF [59]. Finally, even freshwater species, such as the green macroalgae Rhizoclonium hieroglyphicum (C. Agardh) Kützing, are being studied to be used as ingredients in cosmetic products. The aqueous extract of this species was demonstrated to contain PS and AA and its application displayed similar moisturizing effects to hyaluronic acid and glycerin [151].

\subsection{Anti-Aging Products}

Anti-aging products are used to reduce the appearance of aged skin produced by exogenous (environment, smoking, diet, exposure to UV radiation, etc.) and endogenous factors (natural physiological or genetic changes) [13,77]. Some signs of aging are thinning, dryness, laxity, fragility of the skin and the appearance of fine lines and wrinkles. The aging of skin displays itself on several levels. The antioxidant defense system loses the ability to block ROS, raising the oxidative stress status $[13,26]$. In the epidermis and dermis, the number of keratinocytes and melanocytes is reduced, and also the proliferation and migration of the fibroblasts. This situation leads to a reduction in cellular activity and protein synthesis, including collagen [13].

Some seaweed extracts, either from brown, red or green macroalgae, have shown interesting anti-aging effects. Lipophilic extract of the brown macroalgae A. esculenta is already being used in cosmetics, due to its ability to reduce the cutaneous progerin, a truncated version of laminin A, a protein that works with telomeres to trigger cellular senescence in human fibroblasts [23,26]. Another brown alga, M. pyrifera, has been reported to stimulate the synthesis of hyaluronic acid and syndecan-4, both important proteins of the extracellular matrix [23,55]. Extracts of Ecklonia stolonifera Okamura have shown inhibitory effects on the factor $\kappa B(N F-\kappa B)$ and the AP-1, both activators of the enzymatic family of the MMPs $[6,23,26]$. Regarding the red macroalgae, a methanol extract from $C$. pilulifera reduced the expression of MMP-2 and -9 induced by UV exposition in human dermal fibroblast [6,23]. The chemical profile of a P. umbilicalis extract has shown the content of vitamins A, E and C, which have demonstrated their effectiveness in sunscreen formulations for their anti-aging properties, reducing wrinkles and roughness. A combination of extracts obtained from Meristotheca dakarensis Faye and Masuda and J. rubens has been reported to stimulate the synthesis of keratin, glycosaminoglycans and Collagens I and III [55]. Lastly, an aqueous extract of the green seaweed Caulerpa lentillifera J. Agardh may stimulate the synthesis of Collagen I, IV, laminin-5 and glycosaminoglycans [23].

On the other hand, the specific bioactivities of the isolated or purified components of macroalgae extracts have been tested, as individual compounds or as rich fractions in PS, AA or peptides, pigments or phenolic compounds, among others. PS like laminarin, fucoidan and alginate extracted from brown macroalgae, such as F. vesiculous and T. conoides, have demonstrated their anti-oxidative properties and can be applied to prevent skin aging. Few studies have shown the ability of fucoidans to inhibit several MMPs and to reduce the human leucocyte enzyme elastase [26,55]. A fraction of the sulfated galactans from Porphyra haitanensis T. J. Chang and B. F. Zheng (Rhodophyta) has demonstrated its antioxidant activity in aging model mice, as well as its influence on fibroblast migration and proliferation, its capacity for modulating growth factors, increasing skin thickness and elasticity as well as inhibiting matrix MMPs [13].

Some macroalgae peptides, AA and AA derivatives have shown the ability to stimulate collagen production in the skin. Protein hydrolysates from U. pinnatifida, Sargassum spp., P. yezoensis, P. palmata and Enteromorpha prolifera (O.F.Müller) J. Agardh have demonstrated antioxidant properties. A polypeptide from $U$. lactuca stimulated the production of collagen, elastin and increased the biosynthesis of Collagen I in human fibroblasts [13]. The matricines, composed of short chains of 
AA, are capable of stimulating collagen synthesis, but its hydrophilic nature leads to a minimal skin penetration, making matricines weak anti-wrinkle agents [23]. MAAs extracted from P. umbilicalis are used to elaborate anti-wrinkle and antiphotoaging preparations [152]

Carotenoids are liposoluble pigments that inhibit the formation of ROS, such as astaxanthin, which is considered a great antioxidant that prevents skin damage induced by UV radiation and ameliorates age-related macular degeneration [6,23]. It has been reported that fucoxanthin isolated from Hizikia fusiformis (Harvey) Okamura induced the Nrf2-ARE pathway in mouse liver cells, protecting cells from oxidative damage [13].

Phlorotannins obtained from an E. cava extract were able to inhibit MMP activity and also had a protective effect against photo-oxidative stress [23,153]. Dieckol and eckol, both phlorotannins, isolated from Ecklonia stolonifera Okamura, inhibited the expression of MMP-1 in human dermal fibroblast cell in vitro [26,55]. Five phlorotannins, including dieckol and eckol, extracted from Ecklonia kurome Okamura and Ecklonia bicyclis Kjellman, have shown inhibitory effects against hyaluronidase, reducing the formation of wrinkles [153]. The other two antioxidant compounds classified as phlorotannins have been identified from M. pyrifera [77].

Phytohormones, such as abscisic acid, have shown potential inhibition of skin proteases and ROS. Some other lipidic compounds have been found to reduce skin aging, such as two keto-type C18 and one keto C16 fatty acid extracted from U. lactuca, which have shown in vitro and in vivo antioxidant activity [13]. Fucosterol, a natural sterol compound isolated from marine brown macroalgae, have protective effects in human keratinocytes cells irradiated with UVB and also reduces MMP production and expression, and enhanced the Type I procollagen production [26].

Finally, sargachromanol, extracted from S. horneri, has been reported to reduce the expression levels of MMP in UVA-irradiated dermal fibroblasts, and also reduced the formation of intracellular ROS. Hence, this compound could be used in cosmetics to prevent photoaging [26].

\subsection{Skin Whitening}

Whitening products generally inhibit tyrosinase, an enzyme related to melanin synthesis, preventing hyper skin pigmentation and stimulating bleaching [13,23,77]. Fucoxanthin isolated from L. japonica suppressed tyrosinase activity in UVB-irradiated guinea pigs and melanogenesis in UVB-irradiated mice. Phloroglucinol derivatives, secondary metabolites, have shown tyrosinase inhibitory activity due to their ability to chelate copper [26]. The phlorotannins dieckol and 7-phloroeckol from E. cava showed higher inhibitory activity of the tyrosinase than arbutin and kojic acid, two commercial inhibitors used in cosmetic formulations [154]. Other compounds with whitening properties are fucoidans. These compounds are sulfated polysaccharides with a high molecular weight, which can be isolated from several macroalgae species like L. japonica. A study evaluating its whitening activity determined that the high sulfate content of fucoidan was metabolized with the help of flavobacterium RC2-3 enzymes and the degraded fucoidan had favorable tyrosinase inhibitory abilities. This study also determined that the smaller molecular weight fucoidans had a better whitening activity, since fractions between 5 and $10 \mathrm{kDa}$ presented the best tyrosinase inhibitory activity $(62.0 \%)$ and the best antioxidant activity (48.3\%) [50]. Another study also tested the whitening effects of purified fucoidans from $S$. polycystum, showing skin-whitening effects via direct inhibition of tyrosinase and intracellular melanin synthesis, which are good indicators of a promising new cosmetic ingredient [52]. Extracts obtained from S. polycystum, with skin whitening properties, displayed anti-melanogenesis when tested using a cell-free mushroom tyrosinase assay [13]. Other macroalgae extracts that have proved their tyrosinase inhibition capacity are Endarachne binghamiae J. Agardh (Phaeophyceae), Schizymenia dubyi (Chauvin ex Duby) J. Agardh (Rhodophyceae), E. cava (Phaeophyceae), Sargassum siliquastrum (Mertens ex Turner) C. Agardh (Phaophyceae), Dictyopteris membranacea Batters (Phaeophyceae) and E. stolonifera (Phaeophyceae) [26,56]. A lipophilic extract of A. esculenta has demonstrated its ability to reduce the expression of the Pme1 17, a gene implicated in 
the transfer of melanin to melanosomes, so it could be potentially used in age-induced spot removal products [23].

\subsection{Haircare}

Marine macroalgae are rich in trace minerals needed for the correct functioning of the thyroid gland involved in hair growth. Marine macroalgae also represent a source of vitamins, such as those belonging to the B group that strengthens hair [155]. The consumption of seaweeds as a nutritional ingredient is considered to have positive effects on hair growth and health, due to its copper content [33]. Some hair products include macroalgae extracted molecules from brown macroalgae, such as U. pinnatifida, E. cava, L. japonica and Sargassum fulvellum (Turner) C. Agardh; also from red ones like P. palmata, P. tenera, C. crispus or Eucheuma cottonii Weber Bosse. P. palmata possesses a high content of vitamins of the B group that contributes to the regeneration of hair. In vivo assays performed in rats administrated with extracts from $E$. cottonii have shown the ability of the macroalgae compounds to promote hair growth, whereas dieckol-rich extracts from E. cava increased the proliferation of dermal papilla cells and hair growth of rat follicles. Many secondary metabolites of these macroalgae, such as the phlorotannins dieckol, 7-phloroeckol and dioxinodehydroeckol, have been demonstrated to promote hair growth by acting on dermal papilla cells in another animal model, the C57BL/6 mice [156]. Other macroalgae compounds like PS have already been included in the formulation of a few haircare products; for instance, the carrageenan family has been used in hair styling products [59]. The glycosaminoglycans have also been used for hair care for their capacity to control the nutrient transfer between the cells and blood, thus supplying the hair matrix with nutrients that are essential for hair growth. Cosmetic products with glycosaminoglycans have shown positive effects on hair growth and appearance, making the hair stronger, thicker and resistant [157].

\subsection{Oral Care}

As explained before, carrageenans obtained from red seaweeds and fucoidans extracted from brown ones have already been included as ingredients in dentalcare products, such as toothpaste and gels [158]. Carrageenans are used to stabilize emulsions; thus, they are used to provide rheological properties to toothpaste products and to give them a shiny appearance [43]. A wide macroalgae-based extracts study evaluated the activity of more than fifty species against periodontal pathogens. Methanolic extracts of Enteromorpha linza (L.) J. Agardh, Sargassum sagamianum Yendo and $U$. pertusa were reported to have strong inhibitory effects against Prevotella intermedia and Porphyromonas gingivalis. The chemical analysis of the extracts revealed that the main active agents involved in the inhibition of the pathogens were phenolic compounds [159].

\subsection{Anti-Cellulite and Slimming Care}

Cellulite causes alterations in the adipose tissue of the hypodermis region, such as enhanced lipogenesis, decreased lipolysis and lipid storage within the adipocytes. Some constituents of macroalgae, including flavonoids, quercetin and phlorotannins, are lipolytic agents. Dieckol, a phlorotannin, extracted from E. cava, has exhibited its ability for inhibiting the adipogenesis and for downregulating the genes involved in lipid metabolism and adipogenesis [13]. On the other hand, a few topical treatments with the capacity to reduce cellulite include brown seaweed molecules obtained from F. vesiculosus, L. digitata, Furcellaria lumbricalis (Hudson) J.V. Lamouroux (Rhodophyceae) or Pelvetia wrightii Okamura (Phaeophyceae) [13,23]. L. digitata extracts have shown to stimulate blood flow and reduce the appearance of cellulite, but not eliminate it. A formulation containing an aqueous extract of F. lumbricalis and F. vesiculosus has been proved to enhance lipolysis in mature adipocytes and the production of pro-Collagen I in human primary fibroblast. While, a cosmetic product containing extracts from Gelidium cartilagineum (L.) Gailon (Rhodophyceae), Pelvetia canaliculata (L.) Decaisne and Thureta (Phaeophyceae) and L. digitata has been demonstrated to have significant slimming effects [59]. Some other macroalgae species, such as J. rubens and Cystoseira baccata (S. G. Gmelin) P. C. Silva 
(Phaeophyceae), have been proposed for formulating slimming cosmetics, but their capacity has not been scientifically sustained yet [23].

\subsection{Peeling Products}

Peeling products are used to remove dead skin cells, superficial lesions or cosmetic defects without disturbing the natural renewal process of the skin. Different seaweeds have been used in peeling products; for instance, L. digitata and Ulva compressa L. [160]. Recently, sodium alginate-based microparticles were evaluated for their use in the formulation of peeling products. Macroalgae-based microparticles were demonstrated to have similar results to those commercial synthetic balls since both products exfoliated dead skin cells effectively [161].

\section{Conclusions}

The cosmetic industry is a growing sector where the search for new metabolites and ingredients to improve and create innovative products is quite important. Nowadays, consumer preferences have evolved and a more ecological conscience has emerged. Therefore, users demand more natural products, with fewer environmental implications and lower side effects. In this context, macroalgae might entail a rich source of different metabolites, with easy accessibility for obtaining these molecules. In this review, the current knowledge on the topic of macroalgae metabolites for the cosmetic industry has been evaluated and several conclusions have been drawn. Among these metabolites, some groups can be highlighted for their properties and potential cosmetic applications, like polysaccharides, pigments and phenolic compounds. Regarding the type of macroalgae (red, green or brown), the three of them have been explored in search of new compounds, but in general terms, brown and red macroalgae have shown a higher diversity. Macroalgae compounds can be used as additives, excipients and also as the active ingredient of cosmetic formulations, and numerous studies have reported the interesting properties of these compounds. Even though some macroalgae compounds are already used, mainly as thickening or gelling agents, they have a lot more unexplored potential, especially in the sunscreens sector due to their photo protecting and anti-photoaging effects. Macroalgae compounds also show other impressive properties in the anti-aging and skin whitening sectors. Besides, macroalgae could be used for anti-cellulite, peeling and slimming care products, and even to hair and oral care, showing very promising results. To conclude, there exist a vast quantity and diverse new metabolites that can be obtained from macroalgae and their numerous applications; these organisms could be considered an interesting and promising matrix to obtain new raw materials for the formulation of innovative cosmetic products. Furthermore, they could be included into circular economy models, being a sustainable source of bioactive compounds for future industrial applications.

Author Contributions: Formal analysis, C.L.-L., M.F.-C., C.J.-L., M.C., P.G.-O., A.G.P., M.A.P., J.S.-G.; Investigation, C.L.-L., M.F.-C., C.J.-L., M.C., P.G.-O., A.G.P.; Methodology, C.L.-L., M.F.-C., C.J.-L., M.C., P.G.-O., A.G.P.; Supervision, M.A.P. and J.S.-G.; Validation, M.A.P. and J.S.-G.; Writing-original draft, C.L.-L., M.F.-C., C.J.-L., M.C., P.G.-O., A.G.P.; Writing-review and editing, C.L.-L., M.F.-C., C.J.-L., M.C., P.G.-O., A.G.P., M.A.P., J.S.-G. All authors have read and agreed to the published version of the manuscript.

Funding: The research leading to these results received financial support from: Programa de Cooperación Interreg V-A España-Portugal (POCTEP) 2014-2020 (projects Ref.: 0181_NANOEATERS_01_E and Ref: 0377_IBERPHENOL_6_E); Xunta de Galicia for the Axudas Conecta Peme supporting the IN852A 2018/58 NeuroFood Project; EcoChestnut Project (Erasmus + KA202); to Ibero-American Program on Science and Technology (CYTED-AQUA-CIBUS, P317RT0003); European Union's Horizon 2020 and Based Industries Joint Undertaking (JU) under grant agreement No 888003 UP4HEALTH Project (H2020-BBI-JTI-2019).

Acknowledgments: The research funding Interreg V-A España-Portugal (POCTEP) 2014-2020 supported the work of C. Jimenez-Lopez; MICINN supporting the Ramón \& Cajal grant for M.A. Prieto (RYC-2017-22891); Xunta de Galicia and University of Vigo supporting the grant for M. Fraga-Corral (ED481B-2019/096) and the grants for A.G. Pereira (ED481A-2019/0228) and P. García-Oliveira (ED481A-2019/295); to the company AlgaMar (www.algamar.com) for support the grant for C. Lourenço-Lopes; to EcoChestnut Project for support the grant M. Carpena.

Conflicts of Interest: The authors declare no conflict of interest. 


\section{References}

1. Guiry, M.D. How many species of algae are there? J. Phycol. 2012, 48, 1057-1063. [CrossRef] [PubMed]

2. Gao, K.; McKinley, K.R. Use of macroalgae for marine biomass production and $\mathrm{CO} 2$ remediation: A review. J. Appl. Phycol. 1994, 6, 45-60. [CrossRef]

3. Spalding, H.L.; Amado-Filho, G.M.; Bahia, R.G.; Ballantine, D.L.; Fredericq, S.; Leichter, J.J.; Nelson, W.A.; Slattery, M.; Tsuda, R.T. Macroalgae. In Mesophotic Coral Ecosystems; Springer: New York, NY, USA, 2019; pp. 507-536. ISBN 978-3-319-92734-3.

4. Pepper, I.L.; Gentry, T.J. Microorganisms Found in the Environment. In Environmental Microbiology, 3rd ed.; Academic Press: Cambridge, MA, USA, 2015; pp. 9-36. ISBN 9780123946263.

5. Wells, M.L.; Potin, P.; Craigie, J.S.; Raven, J.A.; Merchant, S.S.; Helliwell, K.E.; Smith, A.G.; Camire, M.E.; Brawley, S.H. Algae as nutritional and functional food sources: Revisiting our understanding. J. Appl. Phycol. 2017, 29, 949-982. [CrossRef] [PubMed]

6. Anyanwu, R.C.; Rodriguez, C.; Durrant, A.; Olabi, A.G. Micro-Macroalgae Properties and Applications. In Reference Module in Materials Science and Materials Engineering; Elsevier: Amsterdam, The Netherlands, 2018; pp. 1-28. ISBN 9780128035818.

7. MacArtain, P.; Gill, C.I.R.; Brooks, M.; Campbell, R.; Rowland, I.R. Nutritional Value of Edible Seaweeds. Nutr. Rev. 2007, 65, 535-543. [CrossRef]

8. Burtin, P. Nutritional value of seaweeds. Electron. J. Environ. Agric. Food Chem 2003, 2, 498-503.

9. Silva, M.; Vieira, L.; Almeida, A.P.; Kijjoa, A. The Marine Macroalgae of the Genus Ulva: Chemistry, Biological Activities and Potential Applications. J. Oceanogr. Mar. Res. 2013, 1, 1-6.

10. Mendes, M.; Pereira, R.; Sousa Pinto, I.; Carvalho, A.P.; Gomes, A.M. Antimicrobial activity and lipid profile of seaweed extracts from the North Portuguese Coast. Int. Food Res. J. 2013, 20, 3337-3345.

11. Stefan Sebök, W.H.; Hanelt, D. Development of an innovative ring-shaped cultivation system for a land-based cultivation of marine macroalgae. Aquac. Eng. 2017, 77, 33-41. [CrossRef]

12. Vuong, D.; Kaplan, M.; Lacey, H.J.; Crombie, A.; Lacey, E.; Piggott, A.M. A study of the chemical diversity of macroalgae from South Eastern Australia. Fitoterapia 2018, 126, 53-64. [CrossRef]

13. Bedoux, G.; Hardouin, K.; Burlot, A.S. Bioactive Components from Seaweeds: Cosmetic Applications and Future Development. In Advances in Botanical Research; Elsevier: Amsterdam, The Netherlands, 2014; pp. 346-369. ISBN 9780124080621.

14. Hamed, I.; Özogul, F.; Özogul, Y.; Regenstein, J.M. Marine Bioactive Compounds and Their Health Benefits: A Review. Compr. Rev. Food Sci. Food Saf. 2015, 14, 446-465. [CrossRef]

15. Jurgilevich, A.; Birge, T.; Kentala-Lehtonen, J.; Korhonen-Kurki, K.; Pietikäinen, J.; Saikku, L.; Schösler, H. Transition towards circular economy in the food system. Sustainability 2016, 8, 69. [CrossRef]

16. Saldarriaga-Hernandez, S.; Hernandez-Vargas, G.; Iqbal, H.M.N.; Barceló, D.; Parra-Saldívar, R. Bioremediation potential of Sargassum sp. biomass to tackle pollution in coastal ecosystems: Circular economy approach. Sci. Total Environ. 2020, 715, 136978. [CrossRef] [PubMed]

17. Balboa, E.M.; Moure, A.; Domínguez, H. Valorization of Sargassum muticum biomass according to the biorefinery concept. Mar. Drugs 2015, 13, 3745-3760. [CrossRef] [PubMed]

18. Gallego, R.; Bueno, M.; Herrero, M. Sub- and supercritical fluid extraction of bioactive compounds from plants, food-by-products, seaweeds and microalgae-An update. TrAC Trends Anal. Chem. 2019, 116, 198-213. [CrossRef]

19. Baghel, R.S.; Suthar, P.; Gajaria, T.K.; Bhattacharya, S.; Anil, A.; Reddy, C.R.K. Seaweed biorefinery: A sustainable process for valorising the biomass of brown seaweed. J. Clean. Prod. 2020, 263, 121359. [CrossRef]

20. Baghel, R.S.; Trivedi, N.; Reddy, C.R.K. A simple process for recovery of a stream of products from marine macroalgal biomass. Bioresour. Technol. 2016, 203, 160-165. [CrossRef]

21. Kuda, T.; Taniguchi, E.; Nishizawa, M.; Araki, Y. Fate of water-soluble polysaccharides in dried Chorda filum a brown alga during water washing. J. Food Compos. Anal. 2002, 15, 3-9. [CrossRef]

22. Renner, G.; Audebert, F.; Burfeindt, J.; Calvet, B.; Caratas-Perifan, M.; Leal, M.E.; Gorni, R.; Long, A.; Meredith, E.; O'Sullivan, Ú.; et al. Cosmetics Europe guidelines on the management of undesirable effects and reporting of serious undesirable effects from cosmetics in the European Union. Cosmetics 2017, 4, 1. [CrossRef] 
23. Couteau, C.; Coiffard, L. Chapter 14-Seaweed Application in Cosmetics. In Seaweed in Health and Disease Prevention; Elsevier Inc.: Amsterdam, The Netherlands, 2016; pp. 423-441. ISBN 9780128027721.

24. Etcoff, N.L.; Stock, S.; Haley, L.E.; Vickery, S.A.; House, D.M. Cosmetics as a Feature of the Extended Human Phenotype: Modulation of the Perception of Biologically Important Facial Signals. PLoS ONE 2011, 6, e25656. [CrossRef]

25. Aurora, N.; Agarwal, S.; Murthy, R.S.R. Latest technology advances in cosmaceuticals. Int. J. Pharm. Sci. Drug Res. 2019, 4, 168-182.

26. Wang, H.D.; Chen, C.; Huynh, P.; Chang, J. Exploring the potential of using algae in cosmetics. Bioresour. Technol. 2012, 184, 355-362. [CrossRef]

27. Wang, H.-M.; Chou, Y.-T.; Wen, Z.-H.; Wang, C.-Z.; Chen, C.-H.; Ho, M.-L. Correction: Novel Biodegradable Porous Scaffold Applied to Skin Regeneration. PLoS ONE 2013, 8. [CrossRef]

28. Tataru, G.; Popa, M.; Costin, D.; Desbrieres, J. Microparticles based on natural and synthetic polymers for ophthalmic applications. J. Biomed. Mater. Res. 2012, 100A, 1209-1220. [CrossRef] [PubMed]

29. Einarsson, S.; Brynjolfsdottir, A.; Krutmann, J. Pharmaceutical and Cosmetic USe of Extracts from Algae Obtanable from Saline Hot Water Sources. U.S. Patent PCT/IS2007/000012, 10 July 2010.

30. Stuts, C.S.; Schmid, D.; Zülli, F. Use of an Extract from Snow Algae in Cosmetic Ordermatological Formulations. U.S. Patent US12/760,173, 12 September 2012.

31. Asselineau, D.; Bernerd, F.; Fagot, D.; Pageon, H. Natural and photo-induced aging of the skin: The three dimensional culture approach. J. Soc. Biol. 2003, 197, 63-64. [CrossRef] [PubMed]

32. Balboa, E.M.; Luisa, M.; Nogueira, D.R.; González-lópez, N.; Conde, E.; Moure, A.; Pilar, M. Potential of antioxidant extracts produced by aqueous processing of renewable resources for the formulation of cosmetics. Ind. Crops Prod. 2014, 58, 104-110. [CrossRef]

33. Park, A.M.; Khan, S.; Rawnsley, J. Hair Biology Growth and Pigmentation. Facial Plast. Surg. Clin. N. Am. 2018, 26, 415-424. [CrossRef]

34. Mirmirani, P. Ceramic flat irons: Improper use leading to acquired trichorrhexis nodosa. J. Am. Dermatol. 2010, 62, 145-147. [CrossRef]

35. Monselise, A.; Cohen, D.E.; Wanser, R.; Shapiro, J. What Ages Hair? Int. J. Womens Dermatol. 2017, 3 (Suppl. 1), S52-S57. [CrossRef]

36. Sugiyama, Y. Polysaccharides. In Immunotherapy of Cancer: An Innovative Treatment Comes of Age; Springer: Tokyo, Japan, 2016; pp. 37-50. ISBN 9784431550310.

37. Pereira, L. Seaweeds as source of bioactive substances and skin care therapy-Cosmeceuticals, algotheraphy, and thalassotherapy. Cosmetics 2018, 5, 68. [CrossRef]

38. Fernando, I.P.S.; Kim, K.N.; Kim, D.; Jeon, Y.J. Algal polysaccharides: Potential bioactive substances for cosmeceutical applications. Crit. Rev. Biotechnol. 2018. [CrossRef]

39. Ahmed, A.B.A.; Adel, M.; Karimi, P.; Peidayesh, M. Pharmaceutical, Cosmeceutical, and Traditional Applications of Marine Carbohydrates, 1st ed.; Elsevier Inc.: Amsterdam, The Netherlands, 2014; Volume 73, ISBN 9780128002681.

40. Fertah, M.; Belfkira, A.; Dahmane, E.M.; Taourirte, M.; Brouillette, F. Extraction and characterization of sodium alginate from Moroccan Laminaria digitata brown seaweed. Arab. J. Chem. 2017, 10, S3707-S3714. [CrossRef]

41. Gupta, S.; Abu-Ghannam, N. Bioactive potential and possible health effects of edible brown seaweeds. Trends Food Sci. Technol. 2011, 22, 315-326. [CrossRef]

42. Zargarzadeh, M.; Amaral, A.J.R.; Custódio, C.A.; Mano, J.F. Biomedical applications of laminarin. Carbohydr. Polym. 2020, 232, 115774. [CrossRef] [PubMed]

43. Necas, J.; Bartosikova, L. Carrageenan: A review. Vet. Med. 2013, 58, 187-205. [CrossRef]

44. Domínguez, H. Functional Ingredients from Algae for Foods and Nutraceuticals; Woodhead Publishing Limited: Cambridge, UK, 2013; ISBN 9780857095121.

45. Kraan, S. Algal Polysaccharides, Novel Applications and Outlook. In Carbohydrates_Comprehensive Studies on Glycobiology and Glycotechnology; Elsevier: Amsterdam, The Netherlands, 2017; pp. 489-532.

46. Li, B.; Lu, F.; Wei, X.; Zhao, R. Fucoidan: Structure and bioactivity. Molecules 2008, 13, 1671-1695. [CrossRef]

47. Sabalingam, S.; Jayasuriya, W.J.A.B.N. Pharmaceutical Excipients of Marine and Animal origin: A Review. Biol. Chem. Res. 2019, 6, 184-196. 
48. Cardoso, M.J.; Costa, R.R.; Mano, J.F. Marine origin polysaccharides in drug delivery systems. Mar. Drugs 2016, 14, 34. [CrossRef]

49. Obluchinsksya, E.D.; Makarova, M.N.; Pozharitskaya, O.N.; Shikov, A.N. Effects of Ultrasound Treatment on the Chemical Composition and Anticoagulant Properties of Dry Fucus Extract. Pharm. Chem. J. 2015, 49, 183-186. [CrossRef]

50. Chen, Q.; Kou, L.; Wang, F.; Wang, Y. Size-dependent whitening activity of enzyme-degraded fucoidan from Laminaria japonica. Carbohydr. Polym. 2019, 225, 115211. [CrossRef]

51. Fernando, I.P.S.; Dias, M.K.H.M.; Madusanka, D.M.D.; Han, E.J.; Kim, M.J.; Jeon, Y.J.; Ahn, G. Fucoidan refined by Sargassum confusum indicate protective effects suppressing photo-oxidative stress and skin barrier perturbation in UVB-induced human keratinocytes. Int. J. Biol. Macromol. 2020, 164, 149-161. [CrossRef]

52. Fernando, I.P.S.; Sanjeewa, K.K.A.; Samarakoon, K.W.; Kim, H.S.; Gunasekara, U.K.D.S.S.; Park, Y.J.; Abeytunga, D.T.U.; Lee, W.W.; Jeon, Y.J. The potential of fucoidans from Chnoospora minima and Sargassum polycystum in cosmetics: Antioxidant, anti-inflammatory, skin-whitening, and antiwrinkle activities. J. Appl. Phycol. 2018, 30, 3223-3232. [CrossRef]

53. Pozharitskaya, O.N.; Shikov, A.N.; Obluchinskaya, E.D.; Vuorela, H. The pharmacokinetics of fucoidan after topical application to rats. Mar. Drugs 2019, 17, 687. [CrossRef] [PubMed]

54. Kadam, S.U.; O’Donnell, C.P.; Rai, D.K.; Hossain, M.B.; Burgess, C.M.; Walsh, D.; Tiwari, B.K. Laminarin from Irish brown seaweeds Ascophyllum nodosum and Laminaria hyperborea: Ultrasound assisted extraction, characterization and bioactivity. Mar. Drugs 2015, 13, 4270-4280. [CrossRef] [PubMed]

55. Alparslan, L.; Şekeroğlu, N.; Kijjoa, A. The Potential of Marine Resources in Cosmetics. Curr. Perspect. Med. Aromat. Plants 2018, 1, 53-66. [CrossRef]

56. Guillerme, J.B.; Couteau, C.; Coiffard, L. Applications for marine resources in cosmetics. Cosmetics 2017, 4, 35. [CrossRef]

57. Borowitzka, M.A. High-value products from microalgae-Their development and commercialisation. J. Appl. Phycol. 2013, 25, 743-756. [CrossRef]

58. Bloch, J.F.; Tardieu-Guigues, E. Marine biotechnologies and synthetic biology, new issues for a fair and equitable profit-sharing commercial use. Mar. Genom. 2014, 17, 79-83. [CrossRef]

59. Pimentel, F.B.; Alves, R.C.; Rodrigues, F.; Oliveira, M.B.P.P. Macroalgae-derived ingredients for cosmetic industry-An update. Cosmetics 2018, 5, 2. [CrossRef]

60. Hernandez, E. Lipids, Pharmaceutical and Cosmetic Use. In Kirk-Othmer Encyclopedia of Chemical Technology; John Wiley \& Sons: Hoboken, NJ, USA, 2012.

61. Kim, M.S.; Oh, G.H.; Kim, M.J.; Hwang, J.K. Fucosterol inhibits matrix metalloproteinase expression and promotes type-1 procollagen production in UVB-induced HaCaT cells. Photochem. Photobiol. 2013, 89, 911-918. [CrossRef]

62. Sakthivel, R.; Pandima Devi, K. Evaluation of physicochemical properties, proximate and nutritional composition of Gracilaria edulis collected from Palk Bay. Food Chem. 2015, 174, 68-74. [CrossRef]

63. Debbarma, J.; Madhusudana Rao, B.; Narasimha Murthy, L.; Mathew, S.; Venkateshwarlu, G.; Ravishankar, C.N. Nutritional profiling of the edible seaweeds Gracilaria edulis, Ulva lactuca and Sargassum sp. Indian J. Fish. 2016, 63, 81-87. [CrossRef]

64. Joshi, S.; Kumari, R.; Upasani, V.N. Applications of algae in cosmetics: An overview. Int. J. Innov. Res. Sci. Eng. Technol. 2018, 7, 1269-1278.

65. Mercurio, D.G.; Wagemaker, T.A.L.; Alves, V.M.; Benevenuto, C.G.; Gaspar, L.R.; Maia Campos, P.M.B.G. In Vivo photoprotective effects of cosmetic formulations containing UV filters, vitamins, Ginkgo biloba and red algae extracts. J. Photochem. Photobiol. B Biol. 2015, 153, 121-126. [CrossRef] [PubMed]

66. Draelos, Z.D. Modern moisturizer myths, misconceptions, and truths. Cutis 2013, 91, 308-314.

67. Wang, H.M.D.; Li, X.C.; Lee, D.J.; Chang, J.S. Potential biomedical applications of marine algae. Bioresour. Technol. 2017, 244, 1407-1415. [CrossRef]

68. Dumay, J.; Morançais, M. Proteins and Pigments. In Seaweed in Health and Disease Prevention; Elsevier Inc.: Amsterdam, The Netherlands, 2016; pp. 275-318. ISBN 9780128027936.

69. Bom, S.; Jorge, J.; Ribeiro, H.M.; Marto, J. A step forward on sustainability in the cosmetics industry: A review. J. Clean. Prod. 2019, 225, 270-290. [CrossRef] 
70. Rizzo, R.F.; dos Santos, B.d.N.C.; de Castro, G.F.P.d.S.; Passos, T.S.; Nascimento, M.d.A.; Guerra, H.D.; da Silva, C.G.; Dias, D.d.S.; Domingues, J.R.; de Lima-Araújo, K.G. Production of phycobiliproteins by Arthrospira platensis under different light conditions for application in food products. Food Sci. Technol. 2015, 35, 247-252. [CrossRef]

71. Francavilla, M.; Franchi, M.; Monteleone, M.; Caroppo, C. The red seaweed gracilaria gracilis as a multi products source. Mar. Drugs 2013, 11, 3754-3776. [CrossRef]

72. Pandey, V.D.; Pandey, A.; Sharma, V. Biotechnological applications of cyanobacterial phycobiliproteins. Int. J. Curr. Microbiol. App. Sci. 2013, 2, 89-97.

73. Reis, A.; Mendes, A.; Lobo-Fernandes, H.; Empis, J.A.; Novais, J.M. Production, extraction and purification of phycobiliproteins from Nostoc sp. Bioresour. Technol. 1998, 66, 181-187. [CrossRef]

74. Sonani, R.R. Recent advances in production, purification and applications of phycobiliproteins. World J. Biol. Chem. 2016, 7, 100-109. [CrossRef] [PubMed]

75. Dumay, J.; Morançais, M.; Munier, M.; Le Guillard, C.; Fleurence, J. Phycoerythrins: Valuable proteinic pigments in red seaweeds. In Advances in Botanical Research; Elsevier: Amsterdam, The Netherlands, 2014; Volume 71, pp. 321-343. ISBN 9780124080621.

76. Arad, S.; Yaron, A. Natural pigments from red microalgae for use in foods and cosmetics. Trends Food Sci. Technol. 1992, 3, 92-97. [CrossRef]

77. Ariede, M.B.; Candido, T.M.; Jacome, A.L.M.; Velasco, M.V.R.; de Carvalho, J.C.M.; Baby, A.R. Cosmetic attributes of algae-A review. Algal Res. 2017, 25, 483-487. [CrossRef]

78. Chen, K.; Ríos, J.J.; Pérez-Gálvez, A.; Roca, M. Comprehensive chlorophyll composition in the main edible seaweeds. Food Chem. 2017, 228, 625-633. [CrossRef] [PubMed]

79. Mourelle, M.L.; Gómez, C.P.; Legido, J.L. The potential use of marine microalgae and cyanobacteria in cosmetics and thalassotherapy. Cosmetics 2017, 4, 46. [CrossRef]

80. Matsuura, T.; Mori, I.C.; Ikeda, Y.; Hirayama, T.; Mikami, K. Comprehensive phytohormone quantification in the red alga Pyropia yezoensis by liquid chromatography-mass spectrometry. In Protocols for Macroalgae Research; Francis \& Taylor Group, CRC Press: Boca Raton, FL, USA, 2019; pp. 225-236.

81. Michelet, J.F.; Olive, C.; Rieux, E.; Fagot, D.; Simonetti, L.; Galey, J.B.; Dalko-Csiba, M.; Bernard, B.A.; Pereira, R. The anti-ageing potential of a new jasmonic acid derivative (LR2412): In vitro evaluation using reconstructed epidermis episkin ${ }^{\mathrm{TM}}$. Exp. Dermatol. 2012, 21, 398-400. [CrossRef]

82. Jacinto, M.S.C.; Monteiro, H.R.; Lemos, M.F.L. Impact of the invasive macroalgae Asparagopsis armata on coastal environments: An ecotoxicological assessment. Curr. Opin. Biotechnol. 2013, 24, S75. [CrossRef]

83. Lobo, A.M.; Lourenço, A.M. Biossintese de Produtos Naturais; IST Presse: Lisbon, Portugal, 2007; ISBN 9789728469504.

84. Azmir, J.; Zaidul, I.S.M.; Rahman, M.M.; Sharif, K.M.; Mohamed, A.; Sahena, F.; Jahurul, M.H.A.; Ghafoor, K.; Norulaini, N.A.N.; Omar, A.K.M. Techniques for extraction of bioactive compounds from plant materials: A review. J. Food Eng. 2013, 117, 426-436. [CrossRef]

85. Santos, E.S.; Abreu, M.M.; Saraiva, J.A. Mutielemental concentration and physiological responses of Lavandula pedunculata growing in soils developed on different mine wastes. Environ. Pollut. 2016, 213, 43-52. [CrossRef]

86. Lopes, C.L.; Pereira, E.; Soković, M.; Carvalho, A.M.; Barata, A.M.; Lopes, V.; Rocha, F.; Calhelha, R.C.; Barros, L.; Ferreira, I.C.F.R. Phenolic Composition and Bioactivity of Lavandula pedunculata (Mill.) Cav. Samples from Different Geographical Origin. Molecules 2018, 23, 1037. [CrossRef]

87. Kelman, D.; Posner, E.K.; McDermid, K.J.; Tabandera, N.K.; Wright, P.R.; Wright, A.D. Antioxidant activity of Hawaiian marine algae. Mar. Drugs 2012, 10, 403-416. [CrossRef] [PubMed]

88. Khezri, K.; Saeedi, M.; Maleki Dizaj, S. Application of nanoparticles in percutaneous delivery of active ingredients in cosmetic preparations. Biomed. Pharmacother. 2018, 106, 1499-1505. [CrossRef]

89. Van Tran, V.; Loi Nguyen, T.; Moon, J.Y.; Lee, Y.C. Core-shell materials, lipid particles and nanoemulsions, for delivery of active anti-oxidants in cosmetics applications: Challenges and development strategies. Chem. Eng. J. 2019, 368, 88-114. [CrossRef]

90. Morone, J.; Alfeus, A.; Vasconcelos, V.; Martins, R. Revealing the potential of cyanobacteria in cosmetics and cosmeceuticals-A new bioactive approach. Algal Res. 2019, 41, 101541. [CrossRef] 
91. Taofiq, O.; González-Paramás, A.M.; Martins, A.; Barreiro, M.F.; Ferreira, I.C.F.R. Mushrooms extracts and compounds in cosmetics, cosmeceuticals and nutricosmetics-A review. Ind. Crops Prod. 2016, 90, $38-48$. [CrossRef]

92. Ogaji, I.J.; Nep, E.I.; Audu-Peter, J.D. Advances in Natural Polymers as Pharmaceutical Excipients. Pharm. Anal. Acta 2012, 3, 1-16. [CrossRef]

93. Bellion, C.; Brigand, G.; Prome, J.-C.; Bociek, D.W.S. Identification et Caractérisation des Précurseurs Biologiques des Carraghénanes par Spectroscopie de RMN C13. Carbohydr. Res. 1983, 119, 31-48. [CrossRef]

94. Dea, I.C.M.; McKinnon, A.A.; Rees, D.A. Tertiary and Quaternary Structure in Aqueous Polysaccharide Systems which Model Cell Wall Cohesion: Reversible Changes in Conformation and Association of Agarose, Carrageenan and Galactomannans. J. Mol. Biol. 1972, 68, 153-172. [CrossRef]

95. Renn, D. Biotechnology and the red seaweed polysaccharide industry: Status, needs and prospects. Trends Biotechnol. 1997, 15, 9-14. [CrossRef]

96. Ghanbarzadeh, M.; Golmoradizadeh, A.; Homaei, A. Carrageenans and carrageenases: Versatile polysaccharides and promising marine enzymes. Phytochem. Rev. 2018, 17, 535-571. [CrossRef]

97. Jani, G.K.; Shah, D.P.; Prajapatia, V.D.; Jain, V.C. Gums and mucilages: Versatile excipients for pharmaceutical formulations. Asian J. Pharm. Sci. 2009, 4, 309-323.

98. Nakano, M.; Kouketsu, M.; Nakamura, Y.; Juni, K. Sustained Release of Sulfamethizole from Agar Beads after Oral Administration to Humans. Chem. Pharm. Bull. 1980, 28, 2905-2908. [CrossRef] [PubMed]

99. El-Helw, A.E.R.; El-Said, Y. Preparation and characterization of agar beads containing phenobarbitone sodium. J. Microencapsul. 1988, 5, 159-163. [CrossRef] [PubMed]

100. Sharma, V.; Philip, A.K.; Pathak, K. Modified polysaccharides as fast disintegrating excipients for orodispersible tablets of roxithromycin. AAPS PharmSciTech 2008, 9, 87-94. [CrossRef] [PubMed]

101. Pinheiro, A.C.; Bourbon, A.I.; Cerqueira, M.A.; Maricato, É.; Nunes, C.; Coimbra, M.A.; Vicente, A.A. Chitosan/fucoidan multilayer nanocapsules as a vehicle for controlled release of bioactive compounds. Carbohydr. Polym. 2015, 115, 1-9. [CrossRef]

102. European Union. Regulation (EC) No 1223/2009 of the European Parliament and of the Council of 30 November 2009 on cosmetic products (recast) (Text with EEA relevance). Off. J. Eur. Union 2009, 27, 152-302.

103. Alvarez-Rivera, G.; Llompart, M.; Lores, M.; Garcia-Jares, C. Preservatives in Cosmetics: Regulatory Aspects and Analytical Methods. In Analysis of Cosmetic Products, 2nd ed.; Salvador, A., Chisvert, A., Eds.; Elsevier: Boston, MA, USA, 2018; pp. 175-224. ISBN 9780444635167.

104. Myers, E.; Pritchett, T.; Brettell, T. Determination of Preservatives in Cosmetics and Personal Care Products by LC-MS-MS. Lc Gc N. Am. 2015, 33, 16-22.

105. Basketter, D.; White, I.R. Legislative aspects of cosmetic safety in the European Union: The case of contact allergy. Cosmetics 2016, 3, 17. [CrossRef]

106. Bernauer, U.; Chaudhry, Q.; Coenraads, P.J.; Degen, G.H.; Dusinska, M.; Lilienblum, W.; Nielsen, E.; Platzek, T.; Rousselle, C.H.; van Benthem, J.; et al. Opinion of the Scientific Committee on Consumer safety (SCCS)-Opinion on the safety of the use of Methylisothiazolinone (MI) (P94), in cosmetic products (sensitisation only). Regul. Toxicol. Pharmacol. 2016, 76, 211-212.

107. Sasseville, D. Hypersensitivity to preservatives. Dermatol. Ther. 2004, 17, 251-263. [CrossRef]

108. Schwensen, J.F.; White, I.R.; Thyssen, J.P.; Menné, T.; Johansen, J.D. Failures in risk assessment and risk management for cosmetic preservatives in Europe and the impact on public health. Contact Dermat. 2015, 73, 133-141. [CrossRef]

109. Varvaresou, A.; Papageorgiou, S.; Tsirivas, E.; Protopapa, E.; Kintziou, H.; Kefala, V.; Demetzos, C. Self-preserving cosmetics. Int. J. Cosmet. Sci. 2009, 31, 163-175. [CrossRef] [PubMed]

110. Dreger, M.; Wielgus, K. Application of essential oils as natural cosmetic preservatives. Herba Pol. 2014, 59, 142-156. [CrossRef]

111. Muyima, N.Y.O.; Zulu, G.; Bhengu, T.; Popplewell, D. The potential application of some novel essential oils as natural cosmetic preservatives in a aqueous cream formulation. Flavour Fragr. J. 2002, 17, 258-266. [CrossRef]

112. Abd El-Baky, H.H.; El-Baz, F.K.; El-Baroty, G.S. Natural preservative ingredient from marine alga Ulva lactuca L. Int. J. Food Sci. Technol. 2009, 44, 1688-1695. [CrossRef]

113. Kosanić, M.; Ranković, B.; Stanojković, T. Biological activities of two macroalgae from Adriatic coast of Montenegro. Saudi J. Biol. Sci. 2015, 22, 390-397. [CrossRef] 
114. Choi, M.; Yoo, D.I.; Shin, Y. Preparation of Lip Balm Utilizing Functionalities of Colorants Extracted from Marine Algae. Text. Color. Finish. 2014, 26, 124-130. [CrossRef]

115. Salvador, N.; Gómez Garreta, A.; Lavelli, L.; Ribera, M.A. Antimicrobial activity of Iberian macroalgae. Sci. Mar. 2007, 71, 101-113. [CrossRef]

116. Gago-Dominguez, M.; Castelao, J.E.; Yuan, J.M.; Yu, M.C.; Ross, R.K. Use of permanent hair dyes and bladder-cancer risk. Int. J. Cancer 2001, 91, 575-579. [CrossRef]

117. Europena Commission. Commission Regulation (EU) No 1197/2013 of 25 November 2013 amending Annex III to Regulation (EC) No 1223/2009 of the European Parliament and of the Council on cosmetic products 2013. Off. J. Eur. Union 2013, 315, 34-66.

118. Europena Commission. Commission Regulation (EU) 2015/1298 of July 282015 Amending Annexes II and VI to Regulation (EC) No 1223/2009 of the European Parliament and of the Council on Cosmetic Products; European Parliament, C. of the E.U., Ed.; European Parliament, Council of the European Union: Brussels, Belgium, 2015; Volume 199, pp. 22-23.

119. European Commission. Commission Regulation (EU) No 1004/2014 of 18 September 2014 amending Annex V to Regulation (EC) No 1223/2009 of the European Parliament and of the Council on cosmetic products. Off. J. Eur. Union 2014, 282, 5-8.

120. Nohynek, G.J.; Fautz, R.; Benech-Kieffer, F.; Toutain, H. Toxicity and human health risk of hair dyes. Food Chem. Toxicol. 2004, 42, 517-543. [CrossRef]

121. Scher, R.K. Cosmetics and ancillary preparations for the care of nails: Composition, chemistry, and adverse reactions. J. Am. Acad. Dermatol. 1982, 6, 523-528. [CrossRef]

122. Volpe, M.G.; Nazzaro, M.; Coppola, R.; Rapuano, F.; Aquino, R.P. Determination and assessments of selected heavy metals in eye shadow cosmetics from China, Italy, and USA. Microchem. J. 2012, 101, 65-69. [CrossRef]

123. Wenzel, S.M.; Welzel, J.; Hafner, C.; Landthaler, M.; Bäumler, W. Permanent make-up colorants may cause severe skin reactions. Contact Dermat. 2010, 63, 223-227. [CrossRef] [PubMed]

124. Mittal, R.; Tavanandi, H.A.; Mantri, V.A.; Raghavarao, K.S.M.S. Ultrasound assisted methods for enhanced extraction of phycobiliproteins from marine macro-algae, Gelidium pusillum (Rhodophyta). Ultrason. Sonochem. 2017, 38, 92-103. [CrossRef]

125. Nguyen, H.P.T.; Morancais, M.; Fleurence, J.; Tran, T.N.L.; Dumay, J. Extracting and Purifying Pigment R-phycoerythrin from the Red alga Mastocarpus Stellatus. In Proceedings of the 2018 4th International Conference on Green Technology and Sustainable Development, GTSD, Ho Chi Minh City, Vietnam, 23-24 December 2018; pp. 573-577.

126. Sfriso, A.A.; Gallo, M.; Baldi, F. Phycoerythrin productivity and diversity from five red macroalgae. J. Appl. Phycol. 2018, 30, 2523-2531. [CrossRef]

127. Dumay, J.; Morançais, M.; Nguyen, H.P.T.; Fleurence, J. Extraction and purification of r-phycoerythrin from marine red algae. Methods Mol. Biol. 2015, 1308, 109-117.

128. Wang, L.; Qu, Y.; Fu, X.; Zhao, M.; Wang, S.; Sun, L. Isolation, Purification and Properties of an R-Phycocyanin from the Phycobilisomes of a Marine Red Macroalga Polysiphonia urceolata. PLoS ONE 2014, 9, e101724. [CrossRef]

129. Bayerl, C. Beta-carotene in dermatology: Does it help? Acta Derm. Alp Pannonica Adriat 2008, 17, 160-162, 164-166.

130. Christaki, E.; Bonos, E.; Giannenasa, I.; Florou-Paneria, P. Functional properties of carotenoids originating from algae. J. Sci. Food Agric. 2013, 93, 5-11. [CrossRef] [PubMed]

131. Filon, F.L.; Mauro, M. Sensitization to fragrance mix-1 in patients with contact dermatitis in Nord-East of Italy: 1996-2016 time trend and gender effect. Cosmetics 2019, 6, 22. [CrossRef]

132. Ortiz, K.J.; Yiannias, J.A. Contact dermatitis to cosmetics, fragrances, and botanicals. Dermatol. Ther. 2004, 17, 264-271. [CrossRef] [PubMed]

133. Beauchêne, D.; Grua-Priol, J.; Lamer, T.; Demaimay, M.; Quémeneur, F. Concentration by pervaporation of aroma compounds from Fucus serratus. J. Chem. Technol. Biotechnol. 2000, 75, 451-458. [CrossRef]

134. Harsha, L.; Brundha, M.P. Role of collagen in wound healing. Drug Invent. Today 2020, 13, 55-57.

135. Sudel, K.M.; Venzke, K.; Mielke, H.; Breitenbach, U.; Mundt, C.; Jaspers, S.; Koop, U.; Sauermann, K.; Knussman-Hartig, E.; Moll, I.; et al. Novel aspects of intrinsic and extrinsic aging of human skin: Beneficial effects of soy extract. Photochem. Photobiol. 2005, 81, 581-587. [CrossRef] 
136. Le Lann, K.; Surget, G.; Couteau, C.; Coiffard, L.; Cérantola, S.; Gaillard, F.; Larnicol, M.; Zubia, M.; Guérard, F.; Poupart, N.; et al. Sunscreen, antioxidant, and bactericide capacities of phlorotannins from the brown macroalga Halidrys Siliquosa. J. Appl. Phycol. 2016, 28, 3547-3559. [CrossRef]

137. Ryu, B.M.; Qian, Z.J.; Kim, M.M.; Nam, K.W.; Kim, S.K. Anti-photoaging activity and inhibition of matrix metalloproteinase (MMP) by marine red alga, Corallina pilulifera methanol extract. Radiat. Phys. Chem. 2009, 78, 98-105. [CrossRef]

138. Heo, S.J.; Ko, S.C.; Cha, S.H.; Kang, D.H.; Park, H.S.; Choi, Y.U.; Kim, D.; Jung, W.K.; Jeon, Y.J. Effect of phlorotannins isolated from Ecklonia cava on melanogenesis and their protective effect against photo-oxidative stress induced by UV-B radiation. Toxicol. Vitr. 2009, 23, 1123-1130. [CrossRef]

139. Pavia, H.; Cervin, G.; Lindgren, A.; Aberg, P. Effects of UV-B radiation and simulated herbivory on phlorotannins in the brown alga Ascophyllum nodosum. Mar. Ecol. Prog. Ser. 1997, 157, 139-146. [CrossRef]

140. Swanson, A.K.; Druehl, L.D. Induction, exudation and the UV protective role of kelp phlorotannins. Aquat. Bot. 2002, 73, 241-253. [CrossRef]

141. Heo, S.J.; Jeon, Y.J. Protective effect of fucoxanthin isolated from Sargassum siliquastrum on UV-B induced cell damage. J. Photochem. Photobiol. B Biol. 2009, 95, 101-107. [CrossRef] [PubMed]

142. Kim, J.A.; Ahn, B.N.; Kong, C.S.; Kim, S.K. Protective effect of chromene isolated from Sargassum horneri against UV-A-induced damage in skin dermal fibroblasts. Exp. Dermatol. 2012, 21, 630-631. [CrossRef] [PubMed]

143. Piao, M.J.; Yoon, W.J.; Kang, H.K.; Yoo, E.S.; Koh, Y.S.; Kim, D.S.; Lee, N.H.; Hyun, J.W. Protective effect of the ethyl acetate fraction of Sargassum muticum against ultraviolet B-irradiated damage in human keratinocytes. Int. J. Mol. Sci. 2011, 12, 8146-8160. [CrossRef]

144. Chrapusta, E.; Kaminski, A.; Duchnik, K.; Bober, B.; Adamski, M.; Bialczyk, J. Mycosporine-Like Amino Acids: Potential health and beauty ingredients. Mar. Drugs 2017, 15, 326. [CrossRef]

145. Rastogi, R.P.; Richa; Sinha, R.P.; Singh, S.P.; Häder, D.P. Photoprotective compounds from marine organisms. J. Ind. Microbiol. Biotechnol. 2010, 37, 537-558. [CrossRef]

146. Verdier-Sévrain, S.; Bonté, F. Skin hydration: A review on its molecular mechanisms. J. Cosmet. Dermatol. 2007, 6, 75-82. [CrossRef]

147. Pozharitskaya, O.N.; Obluchinskaya, E.D.; Shikov, A.N. Mechanisms of Bioactivities of Fucoidan from the Brown Seaweed Fucus vesiculosus L. of the Barents Sea. Mar. Drugs 2020, 18, 275. [CrossRef]

148. Kanlayavattanakul, M.; Lourith, N. Biopolysaccharides for skin hydrating cosmetics. In Polysaccharides: Bioactivity and Biotechnology; Springer International Publishing: New York, NY, USA, 2015; pp. 1867-1892. ISBN 9783319162980.

149. Choi, J.S.; Moon, W.S.; Choi, J.N.; Do, K.H.; Moon, S.H.; Cho, K.K.; Han, C.J.; Choi, I.S. Effects of seaweed Laminaria japonica extracts on skin moisturizing activity in vivo. J. Cosmet. Sci. 2013, 64, 193-205.

150. Cai, C.E.; Yang, Y.Y.; Cao, R.D.; Jia, R.; He, P.M. Derivatives from Two Algae: Moisture Absorption-Retention Ability, Antioxidative and Uvioresistant Activity. J. Biobased Mater. Bioenergy 2018, 12, 277-282. [CrossRef]

151. Leelapornpisid, P.; Mungmai, L.; Sirithunyalug, B.; Jiranusornkul, S.; Peerapornpisal, Y. A novel moisturizer extracted from freshwater macroalga [Rhizoclonium hieroglyphicum (C. Agardh) Kützing] for skin care cosmetic. Chiang Mai J. Sci 2014, 41, 1195-1207.

152. Guinea, M.; Franco, V.; Araujo-Bazán, L.; Rodríguez-Martín, I.; González, S. In vivo UVB-photoprotective activity of extracts from commercial marine macroalgae. Food Chem. Toxicol. 2012, 50, 1109-1117. [CrossRef] [PubMed]

153. Sanjeewa, K.K.A.; Kim, E.A.; Son, K.T.; Jeon, Y.J. Bioactive properties and potentials cosmeceutical applications of phlorotannins isolated from brown seaweeds: A review. J. Photochem. Photobiol. B Biol. 2016, 162, 100-105. [CrossRef] [PubMed]

154. Sahin, S.C. The potential of Arthrospira platensis extract as a tyrosinase inhibitor for pharmaceutical or cosmetic applications. South Afr. J. Bot. 2018, 119, 236-243. [CrossRef]

155. Kim, S.-K.; Kim, S.-K.; Bak, S.-S. Hair Biology and Care Product Ingredients from Marine Organisms. In Marine Cosmeceuticals; CRC Press, Taylor\&Francis Group: Boca Ratón, FL, USA, 2012; pp. 201-210.

156. Bak, S.S.; Ahn, B.N.; Kim, J.A.; Shin, S.H.; Kim, J.C.; Kim, M.K.; Sung, Y.K.; Kim, S.K. Ecklonia cava promotes hair growth. Clin. Exp. Dermatol. 2013, 38, 904-910. [CrossRef]

157. Ahsan, H. The significance of complex polysaccharides in personal care formulations. J. Carbohydr. Chem. 2019, 38, 213-233. [CrossRef] 
158. Anil, S.; Venkatesan, J.; Chalisserry, E.P.; Nam, S.Y.; Kim, S.K. Applications of Seaweed Polysaccharides in Dentistry. In Seaweed Polysaccharides: Isolation, Biological and Biomedical Applications; Elsevier Inc.: Amsterdam, The Netherlands, 2017; pp. 331-340. ISBN 9780128098172.

159. Choi, J.S.; Ha, Y.M.; Joo, C.U.; Cho, K.K.; Kim, S.J.; Choi, I.S. Inhibition of oral pathogens and collagenase activity by seaweed extracts. J. Environ. Biol. 2012, 33, 115-121.

160. Fabrowska, J.; Łęska, B.; Schroeder, G.; Messyasz, B.; Pikosz, M. Biomass and Extracts of Algae as Material for Cosmetics. In Marine Algae Extracts: Processes, Products, and Applications; Wiley VCH: Weinheim, Germany, 2015; Volume 2, pp. 681-706. ISBN 9783527679577.

161. Kozlowska, J.; Prus, W.; Stachowiak, N. Microparticles based on natural and synthetic polymers for cosmetic applications. Int. J. Biol. Macromol. 2019, 129, 952-956. [CrossRef]

(C) 2020 by the authors. Licensee MDPI, Basel, Switzerland. This article is an open access article distributed under the terms and conditions of the Creative Commons Attribution (CC BY) license (http://creativecommons.org/licenses/by/4.0/). 